\title{
Resilience and Adaptive Capacity of Aquatic Environmental Law in the EU: An Evaluation and Comparison of the WFD, MSFD, and MSPD
}

\author{
Niko Soininen and Froukje Maria Platjouw
}

Over the past $5^{0}$ years, humans have changed aquatic marine and freshwater ecosystems more rapidly and extensively than in any comparable period in human history. These changes have been the effect of meeting growing needs for aquatic ecosystem services crucial for sustaining economic and social development. ${ }^{1}$ Aquatic ecosystems provide benefits for humans in terms of transport, irrigation and agricultural production, aquaculture and fish production, drinking water, water purification, climate regulation, water retention, disease management, production of renewable energy, and recreation, to name but a few. ${ }^{2}$ Aquatic ecosystems and the related social systems need to maintain their core functions (resilience) to safeguard the provisioning and sustainable use of these services. Accordingly, the ecosystem approach has been the governance concept of choice for international and European policymakers. ${ }^{3}$

Three important European Union (EU) directives regulating the planning and management of aquatic environments embrace the ecosystem approach

* Parts of this research were done under the Winland Project and the BlueAdapt Project, which are funded by the Strategic Research Council of the Government of Finland.

1 United Nations Environment Programme, Millennium Ecosystem Assessment, Living Beyond Our Means. Natural Assets and Human Well-being. Statement of the MA Board (Island Press 2005).

2 B Grizzetti and others, 'Assessing water ecosystem services for water resource management' (2016) 61 Environmental Science and Policy 194.

3 The COP 5 Decision v/6 of the Convention on Biological Diversity (adopted 22 May 1992, entered into force 29 December 1993, 1760 UNTS 79) defines ecosystem approach as following: "The ecosystem approach is a strategy for the integrated management of land, water and living resources that promotes conservation and sustainable use in an equitable way.' See also V De Lucia, 'Competing Narratives and Complex Genealogies: The Ecosystem Approach in International Environmental Law' (2014) 27 Journal of Environmental Law 91; FM Platjouw, Environmental law and the ecosystem approach: Maintaining ecological integrity through consistency in law (Routledge 2016).

(C) NIKO SOININEN AND FROUKJE MARIA PLATJOUW, 2019 | DOI:10.1163/9789004389984_003 This is an open access chapter distributed under the terms of the prevailing CC-BY-NC License at the time of publication. 
as a leading paradigm for their design and scope, either implicitly or explicitly. While the Water Framework Directive (WFD) ${ }^{4}$ seeks to prevent the deterioration of freshwater ecosystems and restore their good ecological status, the Marine Strategy Framework Directive (MSFD) $)^{5}$ seeks to accomplish somewhat similar goals within the marine environment. The Maritime Spatial Planning Directive (MSPD), ${ }^{6}$ although containing a broad set of goals, is designed to help with the implementation of the MSFD. ${ }^{7}$

All three directives have adopted what is commonly referred to as a programmatic approach. In a nutshell, this means that cyclical and evolving plans and programmes are used as primary tools for attaining environmental goals. ${ }^{8}$ This is in line with a widely-accepted view that one of the main mechanisms for achieving the ecosystem approach is adaptive management (and planning). ${ }^{9}$ As emphasized at the international level by the Secretariat of the Convention on Biological Diversity:

The ecosystem approach requires adaptive management to deal with the complex and dynamic nature of ecosystems and the absence of complete knowledge or understanding of their functioning. Ecosystem processes are often non-linear, and the outcome of such processes often show timelags. The result is discontinuities, leading to surprise and uncertainty.

4 Council Directive 2000/60/EC of 22 December 2000 establishing a framework for Community action in the field of water policy [2002] OJ L 327/22.

5 Council Directive 2008/56/EC of 17 June 2008 establishing a framework for community action in the field of marine environmental policy [2008] OJ L164/19.

6 Council Directive 2014/89/EU of 23 July 2014 establishing a framework for maritime spatial planning [2014] OJ L257/135.

7 MSFD preamble 22; European Parliament, 'European Parliament legislative resolution of 17 April 2014 on the proposal for a directive of the European Parliament and of the Council establishing a framework for maritime spatial planning and integrated coastal maritime spatial planning and integrated coastal management' Сом (2013) 0133 .

8 See more on the programmatic approach F Groothuijse and R Uylenburg, 'Everything according to plan? Achieving environmental quality standards by a programmatic approach' in M Peeters and R Uylenburg (eds), EU Environmental Legislation - Legal Perspectives on Regulatory Strategies (Edward Elgar Publishing 2014) 116, 123-125 and 142-143; L Squintani and $\mathrm{H}$ van Rijswick, 'Improving Legal Certainty and Adaptability in the Programmatic Approach' (2016) 28 Journal of Environmental Law 443, 444.

9 See in the marine context AM Farmer and others, KnowSeas. Knowledge-based Sustainable Management for Europe's Regional Seas. The Ecosystem Approach in Marine Management (EU $\mathrm{FP}_{7}$ KnowSeas Project 2012) 5-9. Like the ecosystem approach, adaptive management is a broad concept, and consists of several components, see L Rist, BM Campbell and P Frost 'Adaptive management: where are we now?' (2012) 40(1) Environmental Conservation 5 . 
Management must be adaptive in order to be able to respond to such uncertainties and contain elements of "learning by doing" or research feedback. ${ }^{10}$

In other words, constant changes and uncertainties in ecosystems, or social systems dependant on them, do not allow for the law to settle aquatic management and planning practices with long-term certainty. If we are to achieve the policy goals set in aquatic environmental legislation - mainly the functioning of social ecological systems ${ }^{11}$ - there is a need to make sure that this legislation is up to the task.

It seems safe to assert that " $\mathrm{t}$ ] he need for "adaptive law" - for law to be adaptive and resilient - is clear. What is not as clear, though, is what adaptive law would look like. What would be its primary features?'12 In this chapter, we will first explore the linkages between resilience, adaptivity and the rule of law. This analysis will feed into establishing criteria for a systematic and analytical review of law's resilience and adaptive capacity (the section 'What does social ecological resilience require from the law?). In the section 'Resilience and adaptive capacity of WFD, MSFD and MSPD', we evaluate the Water Framework Directive, the Marine Strategy Framework Directive, and the Maritime Spatial Planning Directive considering these criteria. Geographically, the analysis will cover an ecological continuum from a river basin to the sea, in other words fresh surface waters to coastal waters and marine waters. Groundwater is excluded from the analysis. By laying down the theoretical background and the regulatory design of these directives, we can dissect the possible shortcomings of the programmatic approach in attaining the ecosystem approach, and propose alterations to the legal frameworks in question (section 'Conclusions

10 CBD-COP, Conference of the Parties 5 Decision v/6 'Ecosystem Approach' 2000, (22 June 2000) UNEP/CBD/COP/5/23.

11 C Redman, MJ Grove and L Kuby, 'Integrating Social Science into the Long Term Ecological Research (LTER) Network: Social Dimensions of Ecological Change and Ecological Dimensions of Social Change' (2014) 7 Ecosystems 161, 163 define a social ecological system broadly: 'In this expanded view, what we call the SEs [Social Ecological System] is defined as: 1 . a coherent system of biophysical and social factors that regularly interact in a resilient, sustained manner; 2. a system that is defined at several spatial, temporal, and organizational scales, which may be hierarchically linked; 3 . a set of critical resources (natural, socioeconomic, and cultural) whose flow and use is regulated by a combination of ecological and social systems; and 4. a perpetually dynamic, complex system with continuous adaptation'.

12 GA Arnold and LH Gunderson, 'Adaptive Law and Resilience' (2013) 43 Environmental Law Reporter 10426, 10428. 
and a way forward'). A resilience and adaptive capacity analysis of the three aquatic directives is especially timely as a regulatory (re-)evaluation of the WFD will take place in 2019, and the MSFD will be evaluated in 2023.13 This evaluation provides an opportunity for shifting the existing legal structures where necessary - towards more adaptive aquatic governance.

\section{2 \\ What Does Social Ecological Resilience Require from the Law?}

\subsection{Resilience and Adaptive Law}

Resilience is often defined as a characteristic of a system (whether social, cultural, economic, ecologic, legal) ${ }^{14}$ that can respond - and has the capacity to adapt - to changing circumstances without losing its core functions. ${ }^{15}$ Even though resilience is at its core a descriptive concept (a characteristic of systems) - and not all resilience in all the systems is desirable - the concept has normative implications in legal contexts. As many ecosystem functions are crucial for human survival and prospering, the law needs to safeguard some of these functions (i.e. desirable ecological resilience). ${ }^{16}$ In order to achieve this goal, law as a system needs to have capacity to adapt to changing social ecological circumstances in the systems it seeks to steer without losing its own core characteristics, such as coherence and due process (legal resilience). Designing regulation that has both resilience and adaptive capacity stands at the core of adaptive law theories. ${ }^{17}$ The idea is that law's resilience and adaptive capacity will support and maintain valuable resilience characteristics in social ecological systems the law seeks to steer.

\footnotetext{
13 WFD art. 19; MSFD art. 23.

14 See on the different systems AMH Clayton and NJ Radcliffe, Sustainability: A Systems Approach (Routledge 1996) 21; B Walker and others, 'A Handful of Heuristics and Some Propositions for Understanding Resilience in Social-Ecological Systems' (2006) 11 Ecology \& Society 13, 14: 'Resilience is the capacity of a system to experience shocks while retaining essentially the same function, structure, feedbacks, and therefore identity.'

15 RK Craig, "Stationarity Is Dead" - Long Live Transformation: Five Principles for Climate Change Adaptation Law' (2010) 34 Harvard Environmental Law Review 9, 22; Intergovernmental panel on climate change, Climate Change 2007: Impacts, Adaptation and Vulnerability (Contribution of Working Group II to the Fourth Assessment Report of the Intergovernmental Panel on Climate Change, Cambridge University Press 2007) 727.

16 JB Ruhl, 'General Design Principles for Resilience and Adaptive Capacity in Legal Systems - With Applications to Climate Change Adaptation' (2011) 89 North Carolina Law Review 1373, 1381-1382.

17 See one of the early formulations of adaptive law, JB Ruhl, 'Thinking of Environmental Law as a Complex Adaptive System: How to Clean Up the Environment by Making a Mess of Environmental Law' (1997) 34 Houston Law Review 101, 105-106.
} 
One - although incomplete - answer to the question of why the regulation and management of social ecological systems needs to be adaptive is that these systems are constantly changing, and there are considerable gaps and uncertainties in the human understanding of the systems. ${ }^{18}$ These uncertainties are caused, inter alia, by the lack of scientific data and understanding of biological systems, economic and social risks, and the dynamic and complex nature of social ecological systems. ${ }^{19}$ The constant changes and uncertainty need to be taken seriously, and regulated accordingly. ${ }^{20}$

Some sceptics have questioned whether there is a need for any kind of management of social ecological systems, and whether we could cope with law that did not consider the social ecological consequences of regulation at all. These questions seem to merit in many cases a negative answer. As humans are not only managing social ecological systems, but are part of them affecting their functioning regardless of any management, there is a fundamental need to manage human actions toward and within these systems. Humans have changed and are changing the global ecosystem to such an extent that refraining from management is also a management decision, albeit a passive one. Without active management, human actions would at worst result in the downfall of the core functions of social ecological systems, or at the very least, in an inequitable distribution of costs and benefits emanating from their use. The only question we can rationally ask in this situation is how to manage social ecological systems, and how to regulate this process. ${ }^{21}$

18 CS Holling, Adaptive Environmental Assessment and Management (John Wiley and Sons 1978); CJ Walters, Adaptive Management of Renewable Resources (Macmillan 1986); L Rist and others, 'A New Paradigm for Adaptive Management' (2013) 18(4) Ecology \& Society 63, 64 .

$19 \operatorname{Ruhl}(\mathrm{n} 17)$ 132; Rist and others (n 18) 71.

20 According to Hart, adaptivity is a necessary feature of all legal regulation: 'If the world in which we live were characterized only by a finite number of features, and these together with all the modes in which they could combine were known to us, then provision could be made in advance for every possibility. We could make rules, the application of which to particular cases never called for a further choice. Everything could be known, and for everything, since it could be known, something could be done and specified in advance by rule. This would be a world fit for 'mechanical' jurisprudence. Plainly this world is not our world; human legislators can have no such knowledge of all the possible combinations of circumstances which the future may bring. This inability to anticipate brings with it a relative indeterminacy of aim.' HLA Hart, The Concept of Law (2nd edition, Oxford University Press 1994) 128.

21 This is a somewhat contested claim as the Pardy - Ruhl debate demonstrates, see B Pardy, 'Changing Nature: The Myth of the Inevitability of Ecosystem Management' (2003) 20 Pace Environmental Law Review 675; JB Ruhl, 'The Myth of What is Inevitable Under Ecosystem Management: A Response to Pardy' (2004) 21 Pace Environmental Law Review 
By way of conclusion, adaptive law seeks to establish a close linkage between scientific knowledge of the social ecological systems, and policy responses to their management. ${ }^{22}$ This requires knowledge of how social ecological systems function; how social, cultural, economic and ecological systems interact; and what kind of factors may threaten their core functions. The law needs procedural and substantive mechanisms that allow for new understandings of these different systems to penetrate aquatic management practices. To accomplish this, the core claim of adaptive law scholars is that the law needs to mimic the social ecological systems it seeks to regulate in order to be effective. ${ }^{23}$

\subsection{The Rule of Science and the Law}

Regulatory tools that support resilience of social ecological systems, and their adaptive management, come in different shapes and sizes. First, we can distinguish between substantive and procedural tools. ${ }^{24}$ From a substantive perspective, adaptive law theories often emphasise the need for diverse substantive goals (e.g. aiming on the one hand at protecting ecological processes, and on the other at economic or social uses of natural resources). ${ }^{25}$ The legal tools of choice are often flexible standards or principles that allow managers discretion for considering the insights of the newest scientific knowledge, and changes in technology and values, in managing human actions toward and within the social ecological environment. ${ }^{26}$

From a procedural perspective, law needs to cater for environmental management that facilitates learning. The management process must require

315; B Pardy, 'The Pardy-Ruhl Dialogue on Ecosystem Management Part v: Discretion, Complex-Adaptive Problem Solving and the Rule of Law' (2008) 25 Pace Environmental Law Review 341.

22 MH Benson, 'Integrating Adaptive Management and Oil and Gas Development: Existing Obstacles and Opportunities for Reform' (2009) 39 Environmental Law Reporter 10962: 'It is a method by which scientific research is incorporated in the management actions through an iterative process.' Most often environmental management is divided into trial \& error-management, passive adaptive management, and active adaptive management. For a good overview of the separation between passive and active adaptive management, see BK Williams, 'Passive and active adaptive management: Approaches and an example' (2011) 92 Journal of Environmental Management 1371.

23 Ruhl (n 17) 108; AE Camacho and RL Glicksman, 'Legal Adaptive Capacity: How Program Goals and Processes Shape Federal Land Adaptation to Climate Change' (2016) 87(3) University of Colorado Law Review 711, 722 .

24 See on the separation Ruhl (n 17) 155-159; JB Ruhl (n 16) 1382; E Biber and J Eagle, 'When Does Legal Flexibility Work in Environmental Law?' (2015) 42 Ecology Law Quarterly 787, 793-799.

25 Ruhl (n 17) 155-158; Arnold and Gunderson (n 12) 10429.

26 Arnold and Gunderson (n 12) 10436. 
constant monitoring of the environment, its pressures, and the human - environment interactions, as well as feedback loops that facilitate the integration of new knowledge into developing management practices. ${ }^{27}$ The accumulation of this knowledge is often not possible without involving scientists who have expertise from all the fields of science pertaining to the management of social ecological systems in question, public officials responsible for the management of natural resources, industries whose activities are concerned, and local people who have knowledge and preferences regarding the environment.

The link between adaptive management and the law is discussed in very diverse contexts. First, adaptivity of substantive and procedural law may be discussed at a project level pertaining to the adaptivity of environmental impact assessments, licensing and its conditions, and monitoring. ${ }^{28}$ Second, it can be discussed at the level of plans and programmes seeking to facilitate effective and legitimate regulation of adaptive management of the environmental media more generally. ${ }^{29}$ Bearing in mind the level of abstraction on which the regulation of adaptive management is discussed helps to avoid misunderstandings regarding the tools needed to manage social ecological resilience, or criteria used to measure law's resilience and adaptive capacity to this end.

In the context of aquatic environments, the need to facilitate the ecosystem approach through substantive and procedural regulation at the project level, and at the level of planning can be justified and illustrated by two examples, one from the management of rivers and migratory fish, and another from the management of diffuse pollution of the marine environment.

Illustrating the first example, freshwater ecosystems such as lakes and rivers have been historically subject to heavy structural alterations and usage. For instance in Finland, all the major rivers were licensed for damming to produce hydropower after the second world war, which resulted in a major loss of migratory fish species, such as salmon and trout. ${ }^{30}$ Throughout their lifespan,

27 Ruhl (n 17) 158-159; Arnold and Gunderson (n 12) 10438-10442. On page 10440 they state: 'All four elements are critical: (1) continuous monitoring of multiple indicators of system functions and resilience; (2) assessment of data from monitoring; (3) scientific and social learning from the lessons that the monitoring and assessment provide about the effects of particular decisions or actions; and (4) adaptation of plans, policies, programs, management, governance, and laws based on these lessons learned.'

28 See e.g. M Olszynski, 'Failed Experiments: An Empirical Assessment of Adaptive Management in Alberta's Energy Resources Sector' (2017) 5o University of British Columbia Law Review 697 .

29 See e.g. Squintani and van Rijswick (n 8) 470.

$30 \quad$ B Jonsson and $\mathrm{N}$ Jonsson, 'Fennoscandian freshwater fisheries: diversity, use, threats and management' in JF Craig (ed), Freshwater Fisheries Ecology (Wiley Blackwell 2016) 105. 
hydropower operations and the related licenses have enjoyed strict protection against administrative or legal review that would result in significant economic losses to the plant operator. ${ }^{31}$ In this way, the Finnish legal system has been highly resilient against the restoration of ecological flows and migratory fish species to the Finnish rivers, even though there is no lack of scientific knowledge of the harmful effects of damming on the fisheries and local livelihoods, recreation and tourism. ${ }^{32}$ Here, the permanence (maladaptivity) of earlier legislative, administrative and judicial decisions has resulted in the permanence of hydropower licenses. This example highlights that in some contexts adaptive management needs to deal with problems caused by the law and, from a present perspective, flawed scientific knowledge, rather than by the lack of (present) scientific knowledge. For this reason, adaptive management cannot always - or even often - begin on an empty slate. Maintaining the resilience of freshwater ecosystems, and social and cultural systems of the people relying on them, sometimes requires increasing substantive legal uncertainty. ${ }^{33}$ Here, legal adaptive capacity and one of law's resilience trait (stability of social relations) stand in stark contrast and in need of reconciliation.

The second example of diffuse pollution, however, suggests that safeguarding valuable ecosystem resilience may require a somewhat different legal approach. This is well illustrated by the Baltic Sea which suffers from severe eutrophication. ${ }^{34}$ Here, adaptive management often faces wicked problems caused by the complexity of diffuse pollution as marine waters are the natural drains for rivers and the land-based pollution contained therein. ${ }^{35}$ In this context, there may be a need for increased legal certainty to address non-point source pollution by setting limitations, among others, on agricultural practices. Here, adaptivity may, in substantive terms, require legal certainty and strict legal rules to force adaptivity of agricultural practices that threaten the functioning of the marine ecosystem. ${ }^{36}$

31 A Belinskij and N Soininen, 'Bringing back ecological flows: The case of migratory fish and the Regulation of Hydropower in Finland' (2017) X Ympäristöpolitiikan ja - oikeuden vuosikirja 89, 93-94 (in Finnish).

32 Ibid., 121-122.

33 This is essentially the argument that JB Ruhl made in one of his early papers on adaptive law, see Ruhl (n 17) 107-108.

34 HELCOM, Eutrophication status of the Baltic Sea 2007-2011 - A concise thematic assessment (Baltic Sea Environment Proceedings No. 143, HELCOM 2014) 5-6.

35 Ibid.

$36 \quad$ B Bohman, Transboundary Law for Social-Ecological Resilience. A Study on Eutrophication in the Baltic Sea (Stockholm University 2017) 388. A somewhat similar argument has been presented in discussing the application of art. 6 of the Habitats Directive (Council Directive 92/43/EEC of 21 May 1992 on the conservation of natural habitats and of wild 
Two observations can be made so far. First, the regulation of adaptive management is discussed in substantive and procedural terms, on different levels of abstraction, and in very different social ecological contexts. Stating the social ecological problems that adaptive management seeks to address is paramount for establishing what is required from the law. Without a clear picture of the illness, it is hard to administer a regulatory cure.

Second, environmental regulation should facilitate the inclusion of new scientific knowledge and account for the changes in social ecological systems while holding environmental managers and stakeholders accountable to the (rule of) law and legal certainty. ${ }^{37}$ Legal certainty is important for mainly three reasons: 1) to safeguard legitimate expectations of different actors; 2) to control administrative and judicial powers; and 3) to effectively drive social ecological change in the world (e.g. change towards more effective waste - and run-off water treatment techniques). Without some predictability and permanence of what the law requires, no amount of scientific knowledge or changes in legislation will contribute to the effective achievement of the ecosystem approach (i.e. fostering desired resilience of social ecological systems) because science in itself does not have the force of the law.

To sum up, legal certainty can function as a crucial mechanism for driving adaptive (environmental) changes to social and economic practices, but it can also function as a hindrance to this adaptivity. ${ }^{38}$ Adaptivity, then, has a dual meaning here. First, the law needs to be adaptive to social ecological changes and new knowledge. Second, social ecological systems under management need to be adaptive to the requirements of the law. While the first meaning of adaptivity often requires flexible laws, the second may require more strict laws. Environmental regulation needs to contain both if it is to be effective in effectively managing resilience of social ecological systems and attaining the

fauna and flora [1992] OJ L206/7). See H Schoukens, 'Ongoing activities and Natura 2000 Biodiversity Protection vs Legitimate Expectations?' (2014) 11 Journal for European Environmental \& Planning Law 1 who argues that legal certainty of ongoing activities - such as dredging and forestry - cannot preclude the application of protection rules contained in art. 6 of the Habitats Directive. In other words, the Habitats Directive has (or at least should have) legal force to adapt existing land uses.

37 The rule of law enhances legal certainty in two arenas: between citizens and the government (vertical), and among citizens (horizontal). See J Waldron, 'The concept and the Rule of Law' (2008) 43 Georgia Law Review 1, 8-9.

38 See N Soininen, 'Torn by (un)certainty - Can there be peace between rule of law and other SDGs?' in D French and L Kotzé (eds), Sustainable Development Goals: Law, Theory \& Implementation (Edward Elgar 2018) who analyses how different rule of law theories hinder adaptive management and regulation. 
ecosystem approach to those systems. Law should be a careful combination of adaptivity and certainty, rule of science and the rule of law.

\subsection{Criteria for Evaluating the Resilience and Adaptive Capacity of Environmental Regulation}

Considering the substantive and procedural requirements for adaptive law, and requirements stemming from the rule of law, there is a need to establish how exactly one goes about measuring the resilience and adaptive capacity of environmental regulatory instruments. Academic literature and policy documents are rife with criteria for the task. In the following, we seek to synthesise briefly the main observations and requirements present in the discussion, before moving on to the analysis of the three aquatic EU-directives.

Perhaps not surprisingly, several accounts of legal resilience and adaptive capacity share characteristics. In substantive terms, law should have clear goals against which the legality of environmental management is judged. As discussed in the previous section, these goals must be diverse and must take simultaneously into account environmental, social, and economic aspects. ${ }^{39}$ In general, there are two ways of accomplishing this. The first strategy sets goals of a narrow scope (e.g. purely ecological goals without social or economic considerations) coupled with an exemption regime to remove any undue tensions between different goals and regulatory instruments. The second strategy is to set goals so broad that they can deal with differing environmental, societal and economic needs at the outset. Needless to say, the former regulatory design is much easier to enforce, but may put too much weight on safeguarding ecological resilience at the cost of social and economic resilience (e.g. if public works, such as roads, bridges, production of electricity, or other societally important projects would be weighed against narrow ecological goals).

Procedurally, there would seem to be a rather uniform understanding that regulatory resilience and adaptive capacity require establishing an iterative management process that facilitates learning. The main procedural goals are to reduce scientific uncertainty while securing the rights to information, participation, and access to justice for stakeholders. ${ }^{40}$ It is crucial that these

39 See e.g. Craig (n 15) 40-69; Arnold and Gunderson (n 12) 10428-10432; J McDonald and MC Styles, 'Legal Strategies for Adaptive Management under Climate Change' (2014) 26 Journal of Environmental Law 25, 41-42.

Ruhl (n 16) 1394-1397; AM Keessen and HFMW van Rijswick, 'Adaptation to Climate Change in European Water Law and Policy' (2012) 8(3) Utrecht Law Review 38, 41; Arnold and Gunderson (n 12) 10432-10442; McDonald and MC Styles (n 39) 41-51; Squintani and van Rijswick (n 8) 446. 
iterative processes are accompanied by constant monitoring of the environmental media, as well as human pressures affecting them. ${ }^{41}$ There is also a need for long-term planning processes that are closely linked to substantive regulatory goals and environmental management practices, and integrated and connected across environmental media, sectors, interests and governments. ${ }^{42}$ This connectivity is often understood in terms of linking the different sectors of governance at domestic and transboundary scales, as well as involving the private sector in designing and making governance functional. ${ }^{43}$

Bridging substance and procedure, Robin Craig has suggested that regulatory resilience requires societies to prepare for known unknowns and unknown unknowns (black swans) in environmental management by seeking to boost social ecological resilience where possible, based on scientific knowledge that is available. Building social ecological buffers by improving marine and freshwater biodiversity and improving the chemical composition of the water may help in responding and adapting to future changes, including those caused by climate change. ${ }^{4}$

It is also rather widely acknowledged that regulatory resilience and adaptive capacity are tied to the utilisation of policy instruments outside the scope of direct (legal) regulation. In particular, economic, but also purely voluntary, instruments, such as dissemination of information, are considered crucial complements to the policy mix, in addition to direct regulation. ${ }^{45}$ Overall, governance seeking to safeguard the core functions of social ecological systems needs to facilitate polycentric sources of power and a versatile choice of policy instruments which foster innovative responses to constantly evolving social ecological challenges. ${ }^{46}$

In addition, to facilitate effective enforcement, both substantive and procedural goals must be accompanied by implementing rules - or objectives themselves must be legally binding - to foster compliance with adaptive aquatic planning and management. Furthermore, environmental regulations must set

\footnotetext{
41 Craig (n 15) 40-43.

42 Ibid., 53-63. See also Keessen and van Rijswick (n 40) 41.

43 K Pasteur, From Vulnerability to Resilience. A framework for analysis and action to build community resilience (Practical Action Publishing 2011) 4; UN Water (2017) Water, Food and Energy <http://www.unwater.org/water-facts/water-food-and-energy/> accessed 22 September 2017.

44 Craig (n 15) 43-53.

45 Arnold and Gunderson (n 12) 10432-10436.

46 Ibid., 10436.
} 
certain time limits for reaching the goals, and be linked to obligations and penalties in a case of non-compliance. ${ }^{47}$

Finally, it is important to safeguard a degree of coherence between legal instruments. A coherent understanding of resilience and adaptive capacity in law and governance plays an important part especially in geographical areas where several regulatory and/or governance arrangements overlap. ${ }^{48}$ In our view, coherence is linked to most of the analysis categories presented above. First, substantive coherence is needed to prioritise and/or reconcile mismatching and contradictory substantive goals. Second, coherence is procedurally desirable for facilitating transboundary compatibility of regulation, and easier transposition and implementation of international and transnational legislation at state and local levels. Third, coherence of enforcement regulation may be desirable in supporting the achievement of transboundary legal and policy goals.

Overall, the above set of resilience and adaptive capacity criteria is mostly based on adaptive law and governance literature which often takes a rather critical view towards the rule of law - at least if considered as protecting legitimate expectations based on old laws that are, under present scientific knowledge, misguided in their regulation. ${ }^{49}$ In its most archaic form, the rule of law is seen to require certainty of management decisions, as well as access to courts. ${ }^{50}$ Crudely speaking, the rule of law is said to require permanence of

47 Squintani and van Rijswick (n 8) 446.

48 Given the degree of fragmentation in international, European Union and national environmental law, it is crucial to safeguard coherence within and between pieces of legislation, see House of Lords Committee, European Union Committee, 'The North Sea under pressure: is regional marine co-operation the answer?' (1oth Report of Session 2014-15, House of Lords paper 137, 2015) 94-95. See also FM Platjouw, "Transboundary marine spatial planning in the North Sea - Are national policies and legal structures compatible enough? The case of Norway and the Netherlands' (2018) 33(1) International Journal of Marine and Coastal Law 34. See also Keessen and van Rijswick (n 40) 39. This coherence must, however, be limited by the characteristics of the social ecological environment that is being regulated, see in more detail section 'The rule of science and the law' above.

49 See Craig (n 15) 64-66. Many of the regulatory resilience and adaptive capacity criteria presented above are also visible in EU's aquatic policy, see European Commission, 'Adapting to climate change: Towards a European framework for action, Сом (2009) 147 final 7-16. According to the White Paper, climate change adaptation requires: 1 . building the knowledge base; 2. integrating adaptation into EU policy; 3. Increasing the resilience of coastal and marine areas as well as biodiversity, ecosystems and water; 4. employing a combination of policy instruments, and; 4 . promoting international coordination on adaptation.

$5^{0}$ See J Ebbesson, 'The rule of law in governance of complex socio-ecological changes' (2010) 20 Global Environmental Change (3) 414; B Cosens, 'Transboundary River Governance in 
existing management decisions, as well as predictability and foreseeability of new ones. ${ }^{51}$

While access to court as a procedural criterion is reconcilable with law's adaptive capacity, permanence (finality) of old and new management decisions is not necessarily so. Against this background, it is no surprise that many legal analyses of resilience and adaptive capacity have turned on procedural certainty, while maintaining the position that substantive questions will have to be somewhat open in the face of scientific and policy uncertainties faced in aquatic planning and management. ${ }^{52}$ As always, overly flexible rules are feared because of the discretion left to environmental managers to choose - considering the best science - which management options best satisfy the regulatory goals. While this is a legitimate concern, it bears remembering that the rule of law is no singular concept. The formal conceptions of the rule of law require clear and foreseeable rules, but the procedural conception of the rule of law which maintains that substantive rules may be uncertain if due process is followed in their application - downplays the controversy between the adaptive capacity of the law and the rule of law. ${ }^{53}$ So, too, does the fact that law's resilience requires predictability and permanence from the rules in certain contexts (as opposed to always requiring adaptivity), as demonstrated in section 'The rule of science and the law' above.

From a formal rule of law perspective, it is also important to remember that adaptive law as a theoretical concept is neutral in the sense that it sometimes furthers the cause of the environmentalist (case of bringing back ecological flows to Finnish rivers, and regulating diffuse pollution of the marine environment), and on other occasions the cause of the industrialist (derogating from strict nature conservation for economic and social purposes). The policy choices made in the design of regulatory goals and tools, as well as science

the Face of Uncertainty: Resilience Theory and the Columbia River Treaty' (2010) 30(2) Journal of Land Resources and Environmental Law 229.

51 HC Bugge, 'Twelve Fundamental Challenges in Environmental Law' in C Voigt (ed), Rule of Law for Nature. New Dimensions and Ideas in Environmental Law (Cambridge University Press 2013) 3, 7-8. For many adaptive law scholars, this dichotomy between legal certainty and uncertainty would be too crude. For instance, Keessen and van Rijswick (n 40) 40-41 state that there is a need for the law to facilitate changes in old (poorly guided) environmental management decisions while retaining to the requirement of substantive legal certainty.

$5^{2}$ See e.g. Keessen and van Rijswick (n 40) 41-44 analyzing the importance of multilevel governance, information, participation and access to justice in European water policy. They argue that rule of law sets mainly procedural criteria for resilience, mainly certainty of the laws and access to justice.

See Soininen (n 38$)$. 
regarding the social ecological systems, lock down the answers to the question of whose side adaptivity resides on.

Based on the above discussion, our legal resilience and adaptive capacity criteria are as follows:

TABLE 2.1 Criteria for analysing resilience and adaptive capacity of legal instruments

\begin{tabular}{|c|c|}
\hline $\begin{array}{l}\text { Substance } \\
\text { 1. Plurality of goals, or goals of narrow scope } \\
\text { coupled with exemptions; } \\
\text { 2. Discretion to adjust management in light of } \\
\text { new scientific knowledge. }\end{array}$ & $\begin{array}{l}\text { Procedure } \\
\text { 1. Increasing knowledge; 2. Iteration; } \\
\text { 3. Crossing sectoral, jurisdictional and } \\
\text { public/private boundaries; } \\
\text { 4. Access to information and justice. }\end{array}$ \\
\hline $\begin{array}{r}\text { Regu } \\
\text { resilie } \\
\text { adap }\end{array}$ & $\begin{array}{l}\text { atory } \\
\text { ce and } \\
\text { ivity }\end{array}$ \\
\hline $\begin{array}{l}\text { Instrument choice } \\
\text { 1. Direct regulation coupled with economic } \\
\text { and voluntary instruments. }\end{array}$ & $\begin{array}{l}\text { Enforcement } \\
\text { 1. Legally binding and specific obligations to } \\
\text { achieve procedural and substantive goals; } \\
\text { 2. Time limits for goals; } \\
\text { 3. Sanctioning of non-compliance. }\end{array}$ \\
\hline
\end{tabular}

In the following sections we analyse, using the above criteria, the extent to which the European Water Framework Directive, the Marine Strategy Framework Directive, and the Maritime Spatial Planning Directive fulfil these criteria. Each sub-section in 'Resilience and adaptive capacity of WFD, MSFD and MSPD' begins with a brief overview of each directive followed by the resilience and adaptive capacity analysis. In the section 'Comparing the resilience and adaptive capacity of the three directives' we compare the directives in light of these criteria. Finally, in the section 'Conclusions and a way forward', we evaluate which directive(s) should be used as a model for the future regulatory designs in the field of water and marine policy.

\section{Resilience and Adaptive Capacity of WFD, MSFD and MSPD}

\subsection{Water Framework Directive}

The Water Framework Directive marks a significant change in the European governance of inland surface waters, coastal waters and transitional waters. ${ }^{54}$ 
Instead of a sectorally fragmented system of governance based on administrative and national boundaries, the directive adopts a holistic approach to aquatic environmental protection and regulation. ${ }^{55}$ It requires EU member states to establish river basin districts that are based on geographical and hydrological criteria instead of administrative or political boundaries.

The directive aims at achieving, among other things, Good Ecological Status (GES) of all the said waters by 2015 or, failing that, by 2021 (or 2027 at the latest). ${ }^{56}$ Simultaneously, all the waters are regulated by the non-deterioration clause, which requires $\mathrm{EU}$ member states to implement all the necessary measures to prevent the further deterioration of the water bodies. ${ }^{57}$

In the WFD-system, the assessment of ecological status is primarily based on three or four Biological Quality Elements (BQES) depending on the water body in question. In the context of lakes, the BQEs comprise of 1 ) Composition, abundance and biomass of phytoplankton; 2) Composition and abundance of other aquatic flora; 3) Composition and abundance of benthic invertebrate fauna; and 4) Composition, abundance and age structure of fish fauna. Good Ecological Status requires, on a general level, that the вQES show only a low level of distortion resulting from human activity. ${ }^{58}$ With regard to fish fauna, for instance, the GES requires that there are only slight changes in species composition and abundance attributable to anthropogenic impacts. ${ }^{59}$ In addition to the вQEs, physical-chemical and hydro-morphological quality elements must also be considered in the assessment of the GEs. This evaluation must consider 1) the quality of the structure and functioning of aquatic ecosystems associated with surface waters; 2) the physical-chemical nature of the water and sediment: 3) the flow characteristics of the water; and 4) the physical structure of water bodies. ${ }^{60}$

The substantive goal of good ecological status is implemented via several procedural requirements. First, the directive requires the member states to identify all the river basins in their area, and to ensure appropriate administrative arrangements, including the identification of competent authorities responsible for implementing the WFD. ${ }^{61}$ Second, member states must conduct an analysis of the characteristics of each water body, a review of the

$55 \quad$ Keessen and van Rijswick (n 40) 41-42.

$5^{6}$ WFD art. 4.1(a)(ii); art. 4.1(b)(ii). See on the time limits also Squintani and van Rijswick (n 8 ) 461-462. The directive's other goals, mainly the good chemical status and the good ecological potential, will not be discussed here.

57 WFD art. 4.1(a)(i); art. 4.1(b)(i).

$5^{8}$ WFD annex V.

59 WFD annex $V$.

6o WFD annex V.

61 WFD art. $3.1 ; 3.2$. 
impact of human activity on the status of waters, and an economic analysis of water use in each river basin. ${ }^{62}$

Third, member states must establish a register of all areas lying within each river basin district which have been designated as requiring special protection under specific EU legislation for the protection of their surface water and groundwater or for the conservation of habitats and species directly depending on water. ${ }^{63}$ Fourth, member states shall identify, within each river basin all bodies of water used for the abstraction of water intended for human consumption providing more than $10 \mathrm{~m}^{3}$ a day as an average or serving more than 50 persons, and those bodies of water intended for such future use. ${ }^{64}$

Fifth, member states must establish programmes for the monitoring of the water status. ${ }^{65}$ These monitoring programmes are directly linked to a programme of measures which must also be established for each river basin. Each programme of measures shall include the basic measures and, where necessary, supplementary measures to achieve the ecological objectives of the directive. ${ }^{6}$ Where monitoring or other data indicate that the objectives set under WFD art. 4 for the body of water are unlikely to be achieved, the member state shall ensure that the causes of the possible failure are investigated, relevant permits and authorisations are examined and reviewed as appropriate, the monitoring programmes are reviewed and adjusted as appropriate, and additional measures as may be necessary to achieve those objectives are established. ${ }^{67}$

Finally, member states shall ensure that a river basin management plan is produced for each river basin district lying entirely within their territory. ${ }^{68}$ The river basin management plan shall include the information detailed in WFD annex VII. ${ }^{69}$ In practice, a river basin management plan is a summary of the procedural obligations set by the directive. ${ }^{70}$

\footnotetext{
$62 \quad$ WFD art. 5.1.

63 WFD art. 6.1.

64 WFD art. 7.1.

$65 \quad$ WFD art. 8.1.

66 WFD art. 11.1; 11.2.

67 WFD art. 11.5.

68 WFD art. 13.1.

$69 \quad$ WFD art. 13.4.

70 According to WFD art. 13, a river basin management plan must include: 1 ) a general description of the characteristics of the river basin; 2) mapping the location and boundaries of surface water and groundwater bodies, mapping of the ecoregions and surface water body types within the river basin, identification of reference conditions for the surface water body types; 3 ) a summary of significant pressures and impact of human activity on the status of surface water and groundwater; 4) identification and mapping of
} 
The legal resilience and adaptive capacity criteria established above in section 'Criteria for evaluating the resilience and adaptive capacity of environmental regulation' are visible throughout the directive. Substantively, the ecological emphasis of the goal (good ecological status of waters) is clear from a regulatory perspective, but some scholars have criticised the achievement of good ecological status as being unrealistic. ${ }^{71}$ Furthermore, the ecological goals of the directive may be too narrow to facilitate social ecological resilience. To accommodate a more balanced set of goals (as required by the first analysis criteria), WFD art. 4 contains exemptions from the ecological goals. These exemptions can be justified, inter alia, by force majeure, reasons of overriding public interest, or if the failure to achieve the goals is not within the powers of a member state (i.e. actions of other states are causing the failure to achieve the goals). ${ }^{72}$ The exemption system of the WFD does contain potential to balance different aspects of social ecological systems, but it involves risks, too. Too broad an interpretation of the exemptions would water down the ecological goals of the directive, while too narrow an interpretation could be harmful for achieving social and economic goals outside the scope of the directive. ${ }^{73}$ Overall, the substantive goals of the directive contain great potential for social ecological resilience, but also possible pitfalls. However, a more precise evaluation of the directive's resilience and adaptive capacity will have to wait until more experiences from the implementation of the directive, and the exemptions, are at hand.

The procedural framework of the WFD meets most resilience and adaptive capacity criteria as well. The directive contains several mechanisms for accumulating knowledge of the water bodies. First, the definition of good

protected areas; 5) a map of the monitoring networks established; 6) a list of the environmental objectives established under article 4 of the WFD; 7) a summary of the economic analysis of water use; 8) a summary of the programme(s) of measures adopted; 9) a summary of the public information and consultation measures taken, their results and the changes to the plan made as a consequence; 10) a list of competent authorities; and finally 11) the contact points and procedures for obtaining the background documentation and information.

71 D Paganelli and others, 'Critical appraisal on the identification of Reference Conditions for the evaluation of ecological quality status along the Emilia-Romagna coast (Italy) using M-AMBI' (2011) 62(8) Marine Pollution Bulletin 1725 .

72 WFD art. 4.4-4.7. See also Squintani and van Rijswick (n 8) 463-464.

73 Many of the exemption clauses under WFD art. 4 are tied to a 'disproportionate cost' requirement which has been criticised for being too adaptive and discretionary for the member states considering the ecological goals of the directive, see Squintani and van Rijswick (n 8) 463 . 
ecological status is mostly based on natural sciences, ${ }^{74}$ but an economic analysis of the use of waters is also required..$^{75}$ Second, the directive requires the establishment of monitoring programmes that provide information on the status of waters. Based on constant monitoring, the analysis of the characteristics of waters, the review of human impacts, and the economic analysis of water uses shall be reviewed every six years. ${ }^{76} \mathrm{~A}$ similar re-evaluation interval is set for the reasons for granting exemptions from the goals of the directive, for the programmes of measures, and the overarching river basin management plan. Overall, the directive meets - at least on paper - the first two procedural criteria. ${ }^{77}$

Crossing sectoral, public/private and jurisdictional boundaries in planning is safeguarded through several mechanisms. First, member states must establish an authority (or multiple authorities) for carrying out the obligations set in the WFD. ${ }^{78}$ Second, member states have an obligation to encourage the active involvement of all interested parties in the implementation of the directive. This means other sectoral authorities whose activities are affected by river basin management planning, EU institutions (mainly the Commission), industries, and the public. ${ }^{79}$

Access to information is secured by requiring member states to publish and make available for comments to the public a timetable and work programme for the production of the plan, an interim overview of the significant water management issues identified in the river basin, and draft copies of the river basin management plan. ${ }^{80}$ Transparency at an early stage of planning is desirable as it increases local knowledge in the planning process, and may reduce future legal challenges. ${ }^{81}$

Some authors have criticised the directive for not containing provisions on access to justice. ${ }^{82}$ More specifically, the question has been whether EUcitizens have a right of appeal to enforce the WFD on procedural grounds only (if the planning process violates EU-law), or whether the right of appeal also contains substantive grounds. Currently, the prevailing view is that the WFD

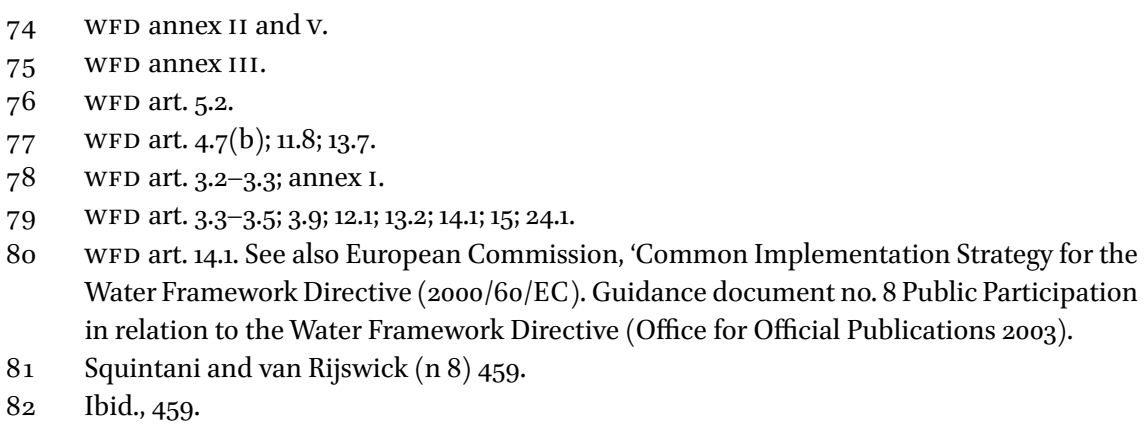


establishes for EU citizens a right to enforce the procedural establishment of plans and programmes required by the WFD. ${ }^{83}$ After the decision of the Court of Justice of the European Union (CJEU) in the Weser case it seems that - as the substantive goals of the directive are legally binding - citizens would have access to court on substantive grounds as well. ${ }^{84}$

Evaluating the third resilience and adaptive capacity criterion (instrument choice), the WFD is based on direct regulation coupled with economic instruments. WFD art. 5.1 requires member states to conduct an economic analysis of water uses in their river basin districts and to take account of the principle of recovery of costs in designing their national legislation. ${ }^{85}$ In this way, some aspects of the third analysis criteria are present on paper but their functionality has been criticised in practice. Keessen and van Rijswick argue that in most EU-countries economic instruments regarding the use of water are not extended beyond payments for drinking water. ${ }^{86}$ The CJEU has emphasised that the cost recovery of water uses is not limited, as per the WFD, to the use of water for drinking. The obligation to price different water uses depends, however, on whether the directive's goals can be achieved without pricing or not. ${ }^{87}$

The fourth resilience and adaptive capacity criterion (enforcement) is secured by procedural and substantive grounds, as discussed above. Furthermore, enforcement is secured by legally binding time limits for the member states in reaching the substantive and procedural goals of the directive. ${ }^{88}$ Finally, the non-compliance of member states is monitored by the Commission (art. $17 \mathrm{TEU}^{89}$ ), and sanctioned by art. 258 of the TFEU under which the European Commission may bring a case before the CJEU after first giving the member state concerned the opportunity to submit observations on its alleged infringement of EU law. While the enforcement of the directive will most

83 See Case 237/07 Dieter Janecek v Freistaat Bayern [2008] ECLI:EU:C:2008:447, and on the analysis Keessen and van Rijswick (n 40) 44.

84 Case 461/13, Bund für Umwelt und Naturschutz Deutschland eVv Bundesrepublik Deutschland [2015] ECLI:EU:C:2015, 433. See on the analysis of the case T Paloniitty, 'The Weser Case: Case C-461/13 BUND V GERMANY' (2016) 28(1) Journal of Environmental Law 151.

$85 \quad$ WFD art. 9.1.

86 Keessen and van Rijswick (n 40) 43.

87 See Case 525/12, European Commission v Federal Republic of Germany [2014] ECLI:EU:C:2014:2202. See on the analysis of the case, A Belinskij, 'Recovery of costs for water uses at the different levels of water law' in E Hollo (ed), Water Resource Management and the Law (Edward Elgar 2017) 213.

88 WFD 4.4-4.5; 4.7-4.8; 5.1; 8.2; 9.1; 11.7; 24.1.

89 Treaty on the Functioning of the European Union (2007) (consolidated version) $2012 \mathrm{OJ}$ C $326 / 47$. 
likely be connected to the procedural implementation of the directive, a door for substantive enforcement has been opened after the Weser case.

Finally, the WFD seeks to safeguard coherence towards other EU-law by establishing an integrated overall framework for water management. ${ }^{90}$ The WFD does not contain regulatory links to the marine directives (MSFD and MSPD) for the obvious reason that it was adopted several years prior to them. For this reason, securing cross-regulatory coherence falls on the marine directives. The resilience and adaptive capacity of these directives will be analysed in the next two sub-sections.

\subsection{Marine Strategy Framework Directive}

The Marine Strategy Framework Directive was adopted on 17 June 2008, after an extensive consultation process including EU member states, third countries, international organisations, key industry and civil society actors, as well as members of the scientific community. ${ }^{91}$ The directive establishes a framework requiring member states to achieve Good Environmental Status (GES) of their marine waters by 2020. ${ }^{92}$ The ultimate goal of the directive is to maintain biodiversity of the seas that are clean, healthy and productive, and to secure sustainable use of the European seas. ${ }^{93}$ The Commission has emphasised that in all community and state actions, priority should be given to achieving or maintaining the GEs. ${ }^{94}$ The Good Environmental Status is defined by the following factors: 1) biological diversity; 2) the level of non-indigenous species; 3) populations of commercial fish and shellfish; 4) elements of marine food webs; 5) eutrophication; 6) sea floor integrity; 7) alteration of hydrographical conditions; 8) contaminants; 9) contaminants in fish and seafood for human consumption; 10) marine litter; 11) introduction of energy, including underwater noise. ${ }^{95}$

The main driver for adopting the directive was to prevent a significant deterioration of the marine environment, ${ }^{96}$ which, in turn, would jeopardise the very basis on which a large part of the European blue economy stands. Second, the directive seeks to tackle sectoral fragmentation of marine environmental

\footnotetext{
$90 \quad$ Squintani and van Rijswick (n 8) 456.

91 European Commission, 'Proposal for a Directive of the European Parliament and of the Council establishing a framework for Community Action in the Field of Marine Environmental Policy (Marine Strategy Directive)' (Communication) Сом (2005) 505 final 2-3.

92 MSFD art. 1.1.

93 MSFD preamble 3 and 4 .

94 MSFD preamble 8.

95 MSFD annex I.

$96 \quad$ European Commission (n 91) 2.
} 
governance. ${ }^{97}$ Third, the Commission saw a need to adopt the MSFD to fulfil compliance with the EU's international obligations under the Convention on Biodiversity, ${ }^{98}$ as well as under several regional seas conventions. ${ }^{99}$

The substantive goal of GES is implemented via several procedural requirements. Procedurally, the directive requires: 1 ) the establishment of national contact points; ${ }^{100} 2$ ) assessment of the ecological condition of the marine areas and drivers affecting it; ${ }^{101} 3$ ) establishment of criteria for measuring the GES; ${ }^{102} 4$ ) programmes of measures to maintain and reach the GES; ${ }^{103}$ and 5) a monitoring programme tasked to keep track of the condition of the marine environment. ${ }^{104}$ The preamble of the MSFD emphasises the role of the programmes of measures describing them as the 'culmination point' for achieving the GES.

Safeguarding the resilience of the marine environment takes central place in the directive. Substantively (the first analysis criterion), the directive seeks to safeguard the functioning of marine ecosystems. It is the marine sister of the WFD. ${ }^{105}$ Similarly to the WFD, the MSFD contains an exemption regime for action or inaction beyond the powers of a member state due to natural causes, force majeure, and projects of overriding public interest. ${ }^{106}$ From a resilience perspective, the biggest substantive question is whether the goals of the MSFD are legally binding on the member states. If they are not binding, the directive risks failing to deliver on adaptation of existing uses of the marine environment into a more ecologically sustainable path. ${ }^{107}$ The Marine Strategy of Finland, for example, clearly states that the Good Environmental Status cannot be achieved, on all accounts, by 2020 as required by the directive. ${ }^{108}$ In

\footnotetext{
97 Ibid.

98 The Convention on Biological Diversity (adopted 22 May 1992, entered into force 29 December 1993) 1760 UnTs 79.

99 European Commission (n 91) 10-11.

$100 \quad$ MSFD art. 7.

101 MSFD art. 8.

102 MSFD art. 9.

103 MSFD art. 11.

104 MSFD art. 13.

105 See on the comparison also Bohman (n 39) 19-20, 80 and 151.

106 MSFD art. 14.1.

107 The present ecological condition of the Baltic Sea is a fine example of the current management and regulatory problems, and the need for more stringent regulatory tools, see HELCOM, Ecosystem Health of the Baltic Sea. HELCOM Initial Holistic Assessment (Baltic Sea Environment Proceedings No. 122, 2010).

108 Programme of measures of the Finnish marine strategy 2016-2021, $4<\mathrm{http} / / \mathrm{www}$ .ymparisto.fi/en-US/Sea/Protection_and_management_of_the_marine_environment/ Development_of_Finlands_marine_strategy> accessed 20 September 2017.
} 
short, the MSFD goals may allow for too much discretion at present to enable support for and maintenance of desirable ecological resilience. ${ }^{109}$

Procedurally (the second analysis criterion), the directive sets clear obligations for the member states to study and constantly monitor the condition of the marine environment and the pressures affecting it. ${ }^{110}$ The states must also establish specific environmental quality targets for their marine areas and introduce measures taking them towards GES. This whole process must be iterated at least every six years taking into consideration the latest scientific knowledge. 111 The need for an adaptive planning process established by the directive is a testament to the uncertainties underlining marine planning and management. ${ }^{112}$ There is knowledge of the changes that are harmful, and of their drivers, ${ }^{113}$ but their cumulative effects and non-linear changes are uncertain. For this reason, the procedural framework needs to allow for developing science and societal needs to be integrated into the marine planning and management processes. In line with resilience principles, the directive emphasises the role of interdisciplinary marine scientific research and monitoring in informed policy making. ${ }^{114}$ To allow for adaptivity to new scientific knowledge, the Commission is empowered to adapt annexes III, IV and v - which establish methodology and criteria for the GES and the monitoring of the marine environment - to scientific and technological progress. ${ }^{115}$

The marine strategy process is run either by a single authority or multiple authorities at the member state level. ${ }^{116}$ In establishing the programmes of

109 Bohman (n 36$) 155^{-156 .}$

110 Scholars are presently seeking to establish general criteria for the monitoring of the marine environment and the impact assessment of human activities, see e.g. A Borja and others, 'Overview of Integrative Assessment of Marine Systems: The Ecosystem Approach in Practice' (2016) 3 Frontiers in Marine Science 1.

111 MSFD art. 17.2.

112 The preamble 34 of MSFD establishes that '[i]n view of the dynamic nature of marine ecosystems and their natural variability, and given that the pressures and impacts on them may vary with the evolvement of different patterns of human activity and the impact of climate change, it is essential to recognise that the determination of good environmental status may have to be adapted over time'.

113 European Commission (n 91) 4-5: 'The principal threats to the marine environment that were identified include effects of climate change; impacts of commercial fishing; oil spills and discharges; introduction of non-native species; eutrophication and the related growth of harmful algal blooms; litter pollution; contamination by dangerous substances and microbiological pollution; radionuclide discharges; and noise pollution.' The result of this analysis was that the European seas are 'at high risk'.

114 MSFD preamble 23; MSFD annex I, III and IV.

115 MSFD art. 24.1.

116 MSFD art. 7.1. 
measures, member states are obliged to consult competent authorities in the field of water and nature conservation policy. The inclusion of other sectoral authorities in planning is left to the discretion of the member states. ${ }^{117}$ In addition, member states shall, where practical and appropriate, use existing regional institutional cooperation structures, including those under Regional Sea Conventions, covering the relevant marine region or subregion. ${ }^{118}$ The directive also embraces - at least as a matter of black letter law - an inclusive approach towards stakeholder and public participation. Member states shall ensure that all interested parties are given early and effective opportunities to participate in the implementation of the MSFD. ${ }^{119}$ This means that member states shall publish, and make available to the public for comment, summaries of the initial assessment and the determination of good environmental status, environmental targets, monitoring programmes, and programmes of measures. ${ }^{120}$

Overall, the inclusion of several sectoral authorities at the national and international levels is secured, as is public access to information. It is unlikely, however, that stakeholders or the public would have access to court on any other than procedural grounds. At some point, the CJEU will likely be asked to deliberate on this issue. From a procedural resilience and adaptive capacity perspective, then, the MSFD is a mixed bag containing most of the crucial elements but some potential challenges, too.

Considering the third analysis criterion (instrument choice), the directive combines direct regulation with the latest available science. Economic instruments are required in evaluating the alternative costs of degrading marine environments if no action is taken towards improving the ecological condition. ${ }^{121}$ The member states shall also ensure that measures to achieve or maintain GES are cost-effective and technically feasible, and shall carry out impact assessments, including cost-benefit analyses, prior to the introduction of any new measure. ${ }^{122}$ The directive does not, however, explicitly link such economic analysis to the management (e.g. licensing) of development activities in marine areas.

Evaluating the fourth analysis criterion (enforcement), the Commission opted for a framework directive, instead of a regulation or a more prescriptive directive, as it saw that these two regulatory strategies would have neglected

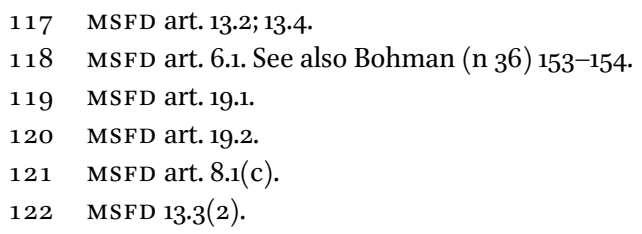


'the diversity of conditions and needs in the EU's marine environment by not allowing Member States to make a number of policy choices for implementation at regional level.'123 It did, however, leave broad discretion to the member states to derogate from the GES if reasons outside the powers of individual member states prohibited them from taking effective action. ${ }^{124}$ It also acknowledged that the GES may not be achieved by 2020 throughout the EU. ${ }^{125}$

To safeguard some level of enforcement, the Commission did not opt for a non-binding recommendation because it was not convinced that the member states would commit to 'rigorous implementation' of the regulatory goals in the absence of any binding obligations. ${ }^{126}$ Rather, the directive may be enforced on procedural grounds if a member state fails to transpose the directive into its national legislation, or fails to establish the procedures required by the MSFD. Substantive enforcement is, however, uncertain. If the CJEU adopts a similar approach to the substantive bindingness of the MSFD goals as it did regarding the goals of the WFD in the Weser case, the MSFD will come to have a significant role in improving the ecological condition of the European seas by adapting unsustainable marine management through increased ecological certainty. ${ }^{127}$ This is, however, unlikely since, first, the WFD is written substantively in much more binding language than the MSFD. Second the WFD is much more detailed and technical compared to the MSFD. Third the MSFD places heavier emphasis on the marine planning procedure, at the expense of substantive obligations. ${ }^{128}$

Finally, the MSFD emphasises the need for coherence across EU's policy sectors (the fifth analysis criterion). ${ }^{129}$ On a more concrete level, this is visible in: 1) demarcating the regulatory line between the WFD and the MSFD regarding coastal waters; ${ }^{130} 2$ ) the role of nature conservation established under the

\footnotetext{
123 European Commission (n 91) 7.

124 MSFD preamble $30-31$ includes two justifications for not acting to achieve the goals: 1) action or inaction or other countries of which MS is not responsible, force majeure, overriding national interest, or natural conditions do not permit the achievement of the goals (preamble (30); 2) EU-wide or international action needed (preamble (31)).

125 MSFD preamble 29.

126 European Commission (n 91) 7 .

127 Case 461/13, Bund für Umwelt und Naturschutz Deutschland eV v Bundesrepublik Deutschland [2015] ECLI:EU:C:2015:433.

128 See in detail Table 2.2 .

129 MSFD preamble 9.

130 MSFD preamble 12.
} 
Habitats Directive ${ }^{131}$ and the Birds Directive ${ }^{132}$ for achieving the GEs; ${ }^{133} 3$ ) a requirement to consider the effects of the Common Fisheries Policy on the GES; ${ }^{134} 4$ ) an obligation for transboundary marine planning and management; ${ }^{135}$ and 5) an obligation to develop common EU-wide methodology for establishing the GES and monitoring the marine environment. ${ }^{136}$ With these provisions, the MSFD is well on its way to providing a sound regulatory basis for coherence between legal instruments that have an aquatic environmental agenda. ${ }^{137}$ Coherence with instruments embracing socio-economic goals may, however, be a different story. We analyse one such instrument, the MSPD, in the following sub-section.

\subsection{Maritime Spatial Planning Directive}

On 23 April 2014, the parliament and the council adopted the Framework Directive for Maritime Spatial Planning, establishing an EU-wide framework for MSP. ${ }^{138}$ The MSPD recognizes that

[t]he high and rapidly increasing demand for maritime space for different purposes, such as installations for the production of energy from renewable sources, oil and gas exploration and exploitation, maritime shipping and fishing activities, ecosystem and biodiversity conservation, the extraction of raw materials, tourism, aquaculture installations and underwater cultural heritage, as well as the multiple pressures on coastal resources, require an integrated planning and management approach. ${ }^{139}$

131 Council Directive 92/43/EEC of 21 May 1992 on the conservation of natural habitats and of wild fauna and flora [1992] OJ L 206/7.

132 Council Directive 2009/147/EC of the European Parliament and of the Council of 30 November 2009 on the conservation of wild birds [2009] OJ L 20/7.

133 MSFD preamble 6.

134 MSFD preamble 40.

135 MSFD preamble 13.

136 MSFD preamble 25 .

137 The integrative role of the MSFD has also been highlighted by Bohman (n 36) 156-159.

138 Most commonly, MSP is referred to as marine spatial planning but the Commission of the European Union - and accordingly the MSPD - uses the concept of maritime spatial planning to refer to the same instrument. See on the conceptual differences between the EU and other parts of the world, H Backer, 'Trans-boundary Maritime Spatial Planning: a Baltic Sea Perspective' (2011) 15 Journal of Coastal Conservation 279.

139 MSPD preamble 1. 
Marine spatial planning has been identified as a cross-sectoral tool supporting the implementation of an Integrated Maritime Policy in the EU. ${ }^{140}$ MSP has been described as 'an integrated and balanced tool that has the potential to provide long-term stability and predictability, as well as to manage competition for space in intensively used areas. ${ }^{141}$ In the Roadmap for Maritime Spatial Planning, which the Commission adopted in 2008, the ecosystem approach was highlighted as an overarching approach for MSP. ${ }^{142}$ The European Commission emphasises that even though a great deal of marine spatial planning can be achieved at the national level, the Commission considers it important to pursue action at the EU level to achieve a coherent framework for MSPs within the EU. A common approach would enable efficient and smooth application of MSPs in cross-border marine areas, favouring the development of maritime activities and the protection of the marine environment based on a common framework and similar legislative implications. MSP is also crucial for legal certainty, predictability and transparency, reducing the costs to investors and operators, particularly those operating in more than one EU member state. ${ }^{143}$

With the MSPD, the Commission opted for a framework directive that requires the establishment of a procedural framework, and includes, as a minimum obligation, the establishment of a spatial planning process for the sea. ${ }^{144}$ Such a planning process should take into account land-sea interactions and promote cooperation among the member states. ${ }^{145}$ Pursuant to article 6 , member states shall, among other things, ensure the involvement of stakeholders, organise the use of the best available data, ensure transboundary cooperation between member states, and promote cooperation with third countries. Member states remain responsible and competent for designing and determining, within their marine waters, the format and content of such plans, including institutional arrangements and, where applicable, any apportionment of

140 European Commission, 'An Integrated Maritime Policy for the European Union' (Blue Paper) сом (2007) 574 final; European Commission, 'Action Plan on an EU Integrated Maritime Policy' SEC (2007) 575 final.

141 European Commission, 'Maritime Spatial Planning in the EU - Achievements and future development' сом (2010) 771, 2.

142 European Commission, 'Roadmap for Maritime Spatial Planning: Achieving Common principles in the EU' СОM (2008) 791 final.

143 European Commission ( $n$ 141) 1. For a summary of the policy background of EU's MSPlegislation, see N Soininen, 'Marine spatial planning in the European Union' in D Hassan, T Kuokkanen and N Soininen (eds), Transboundary Marine Spatial Planning and International Law (Routledge/Earthscan 2015) 189.

144 MSPD preamble 8.

145 MSPD preamble 9. 
marine space to different activities and uses respectively. ${ }^{146}$ Moreover, the Commission decided that the MSPD should not impose any new obligations, but should rather aim to contribute to existing policies through the planning process. ${ }^{147}$ The goals set by the directive are formulated so broadly, that a large degree of discretion is left to the member states in implementing them.

Substantively (the first analysis criterion), the directive promotes sustainable blue growth, sustainable development of marine areas and sustainable use of marine resources. ${ }^{148}$ It does not, however, set (m)any substantive obligations for the member states. ${ }^{149}$ The directive does, however, require the member states to aim to contribute to the sustainable development of energy sectors at sea, of maritime transport, and of the fisheries and aquaculture sectors, and to the preservation, protection and improvement of the environment, including building resilience to climate change impacts. Other objectives may also be pursued, such as the promotion of sustainable tourism and the sustainable extraction of raw materials. ${ }^{150}$ The MSPD respects the member states' prerogatives to tailor the content of the plans and strategies to their specific economic, social and environmental priorities, as well as their national sectoral policy goals and legal traditions. The member states themselves determine how the different goals are reflected and weighted in their marine spatial plan(s). ${ }^{151}$ From a legal resilience and adaptive capacity perspective, this approach respects the plurality of social ecological goals, but it is uncertain what the added value of MSPD is substantively. Furthermore, one can ask whether the directive has the legal force to transform existing - or steer new spatial planning practices at sea. Much of the criticism addressed at the ambiguity of the MSFD's objectives is amplified with the MSPD.

Procedurally (the second analysis criterion), the directive endorses an iterative and adaptive planning process noting that marine spatial planning should cover the full cycle of problem and opportunity identification, information collection, planning, decision-making, implementation, revision or updating, and the monitoring of implementation. ${ }^{152}$ In addition, an ecosystem-based

146 MSPD preamble 11.

147 MSPD preamble 9; art. 2.3.

148 MSPD art. 1.1.

149 See Soininen (n 143$) 192$.

$150 \quad$ MSPD art. 5.1.

151 MSPD art. 5.3. See also European Parliament, "European Parliament legislative resolution of 17 April 2014 on the proposal for a directive of the European Parliament and of the Council establishing a framework for maritime spatial planning and integrated coastal maritime spatial planning and integrated coastal management' СОМ (2013) 0133.

$15^{2}$ MSPD preamble 18. 
approach should be applied in a way that is adapted to the specific ecosystems and other specificities of the different marine regions. This approach will also allow for adaptive management of marine areas which ensures refinement and further development as experience and knowledge increase, and takes into account the availability of data and information at sea-basin level to implement that approach. ${ }^{153}$ The directive requires member states to review their marine spatial plans at least every 10 years. ${ }^{154}$

The directive also crosses sectoral and jurisdictional boundaries. Marine spatial planning is a cross cutting policy tool enabling public authorities and stakeholders to apply a coordinated, integrated, and transboundary approach. ${ }^{155}$ The directive requires cooperation among member states with the aim of ensuring that marine spatial plans are coherent and coordinated across the marine region concerned. ${ }^{156}$ The directive also endorses an inclusive approach towards stakeholder and public participation by requiring member states to establish means of public participation by informing all interested parties and by consulting relevant stakeholders and authorities, and the public concerned, at an early stage in the development of marine spatial plans. The stakeholders and the public should also have access to the plans once finalised. ${ }^{157}$

Considering the third resilience and adaptive capacity criterion (instrument choice), the directive mainly, if not only, uses direct regulation to foster marine spatial planning. The directive does not prescribe the use of any economic or voluntary instruments. Member states will design and determine the format and content of marine spatial plans, including the institutional arrangements. ${ }^{158}$ Overall, the directive itself does not facilitate a versatile choice of policy instruments.

The directive may be enforced (the fourth analysis criterion) on procedural grounds if a member state fails to transpose the directive into its national legislation, or fails to establish the MSP process required by the MSPD. Time limits have been set for the designation of authorities, the establishment of marine spatial plans, and the bringing into force of laws, regulations and administrative provisions necessary to comply with the directive. ${ }^{159}$ Substantive enforcement is, however, uncertain or even unlikely given the large degree of discretion left to member states. In practice, it will be rather difficult, if not impossible,

\footnotetext{
153 MSPD preamble 14.

154 MSPD art. 6.3.

155 MSPD preamble 3.

156 MSPD art. 11.

157 MSPD art. 9.

$15^{8}$ MSPD preamble 11.

159 MSPD art. 15.
} 
to assess whether member states' MSPs, including the procedural steps listed in article 6, support the wide objectives listed in article 5. Objectives such as 'sustainable development' and 'the protection of the environment' will render any substantive enforcement complicated.

Finally, the MSPD emphasises the need for coherence across the EU's policy sectors. This is visible in: 1) aligning the timelines for marine spatial plans with the timetables set out in other relevant legislation, including the MSFD;160 2) defining the geographical scope for marine spatial planning in conformity with existing legislative instruments of the Union and the international law of the sea; ${ }^{161} 3$ ) requiring that marine spatial planning should apply an ecosystem-based approach as referred to in the MSFD art. 1.3 with the aim of ensuring that collective pressure of all activities is kept within levels compatible with the achievement of GES; ${ }^{162} 4$ ) requiring that MSPs will contribute to achieving the aims of the WFD, the MSFD, the Habitats Directive and the Birds Directive, and others; ${ }^{163}$ and defining the term 'marine regions' as referred to in the MSFD article $4,{ }^{164}$ 'marine waters' as in the MSFD article 3 , and 'coastal waters' as in the WFD article $2 .{ }^{165}$

Overall, supporting and maintaining the resilience of the social ecological marine environment through the five legal criteria established above in section 'Criteria for evaluating (...)' takes a central place in the preamble of the directive, but is on a modest footing in the directive itself. On one hand, the degree of discretion within the substantive goals of the directive is significant, rendering substantive enforcement uncertain. On the other hand, the use of marine spatial planning as a planning tool to attain a more ecosystem-based governance approach to the marine regions in Europe may certainly enhance the social ecological resilience of these areas. ${ }^{166}$ The adaptive process of the MSPD is its strongest suit from a regulatory resilience and adaptive capacity perspective.

\subsection{Comparing the Resilience and Adaptive Capacity of the Three Directives}

The Water Framework Directive, the Marine Strategy Framework Directive, and the Maritime Spatial Planning Directive all seek the ecosystem approach

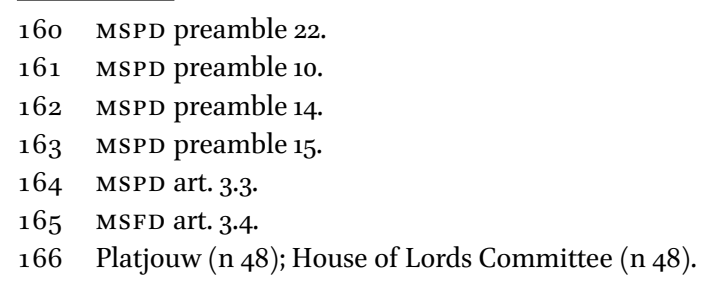


to aquatic governance. They utilise a programmatic and adaptive regulatory approach to achieve this goal. The WFD and the MSFD prioritize ecological goals within that ecosystem approach, while the MSPD seeks to reconcile the ecosystem approach with the EU's Blue Growth agenda. In sustainability language, the WFD and the MSFD seek primarily ecological sustainability, while the MSPD seeks sustainable development. The three directives differ significantly in the way they seek to fulfil the ecosystem approach.

One immediate observation from studying the three directives side by side is that they are wildly different in terms of complexity and level of regulatory detail. An introduction to the WFD requires several pages, while the MSFD and MSPD can be summarised in a couple of paragraphs. The same observation can be made from Table 2.2 (annexed to this chapter) which lays out the regulatory resilience and adaptive capacity analysis in more detail. It is hard to avoid thinking that particularly the WFD has suffered, and will continue to suffer, from implementation and enforcement problems due to this complexity. Even resilient and adaptive laws need to be clear in what they ask of the regulatory subjects, in this case the EU member states.

In terms of substantive resilience and adaptive capacity analysed in this article all the three directives have capacity to support social ecological resilience, but contain different tools for achieving this. While the WFD and the MSFD prioritise ecological goals, they contain a broad exemption system that can be used to secure social and economic goals at a member state level. The MSPD does not require an exemption system for two primary reasons: because it does not contain (m)any substantive obligations; and because its goals are versatile, embracing ecological, social and economic goals simultaneously.

Because of the differences in substantive goals, the resilience and adaptive capacity challenges facing the three directives are also quite different. The MSPD faces the problem of not having enough legal force to adapt existing marine spatial planning practices (or steer new ones) in the member states onto an ecological path. Quite the opposite, the WFD and the MSFD may suffer from overt formalism which, at worst, would turn a blind eye to other than ecological aspects of resilience. The exemption systems of the WFD and the MSFD need to balance a strict interpretation of their goals. Too loose an interpretation will, however, be likely to water down even the strictest of ecological goals. From a resilience and adaptive capacity perspective, this would be problematic as well because blue economies rely on the ecological output and capacity which the WFD and the MSFD seek to protect.

From a procedural perspective (the second analysis criterion), the three directives utilise an iterative and adaptive planning process that seeks to secure broad participation, access to information, and access to justice. The directives differ wildly, however, in their linkages to scientific knowledge. While the WFD 
and the MSFD are directly linked to the best available science in categorising and classifying fresh and marine waters, the MSPD's knowledge is more of the policy kind. All three directives seek to bridge sectoral and public private gaps, and force, or coerce, transboundary cooperation in planning. The procedural design of the directives draws heavily from the adaptive governance literature and, overall, scores high in regulatory resilience and adaptive capacity.

All the three directives are based on direct regulation (the third analysis criterion). The WFD and the MSFD also contain economic instruments. Within the WFD system, the principle of recovery of costs is designed to accommodate the pricing of water uses, and to drive the external costs for water uses into the price of commodities and services provided by water. Within the MSFD, economic instruments are mostly utilised for evaluating the alternative costs of not taking measures to improve the ecological condition of the European seas, and evaluating the costs of the measures that are taken. Interestingly, all the three directives rely heavily on direct regulation despite their effort to broaden the policy mix towards more progressive conceptions of governance. All three directives leave, however, discretion to the member states to decide the measures needed to achieve the substantive goals of the directives. In this way, voluntary measures are also encouraged.

The fourth criterion (enforcement) is a mixed bag. While all three directives are procedurally enforceable, and create rather clear procedural obligations for the member states, the substantive goals and obligations are trickier to enforce. Considering the recent judgment(s) of the CJEU (particularly the Weser case), the WFD seems to be substantively enforceable, while the jury is still out on the MSFD. The MSPD, as it does not contain (m)any substantive obligations, is not substantively enforceable against the member states. Overall, the freedom for the member states to craft national and local solutions to aquatic environmental problems is a positive feature from a social ecological resilience perspective; however, it also gives rise to risks in safeguarding the ecological basis of those systems.

The final criteria (cross-categorical coherence) is the most difficult to evaluate. While the three directives contain many substantive and procedural similarities, they are also very different as stated above. One of the biggest problems for evaluating coherence between the three directives - or towards other EU-law - is the openness of the MSFD and the MSPD on one hand, and the complexity of the WFD on the other. Nevertheless, the MSFD is closely linked in its scope and definitions to the WFD. Moreover, the linkages between the MSFD and the MSPD are close, and marine spatial planning is often seen as one of the tools in the overarching framework of marine planning. Thus, in conclusion, at least a modest notion of coherence is achieved. 


\section{Conclusions and a Way Forward}

This chapter has focused on the resilience and adaptive capacity of aquatic environmental law in the EU. We studied the linkages between resilience, adaptivity and the rule of law, and sought to systematise criteria for the evaluation of regulatory resilience and adaptive capacity. Three important EU directives have been evaluated and compared in light of these criteria. We concluded that the WFD, the MSFD, and the MSPD differ in the way they seek to fulfil the ecosystem approach, as well as in their degree of regulatory resilience and adaptive capacity. In the following conclusions, we suggest a regulatory design which combines the triumphs of the WFD, the MSFD and the MSPD, while overcoming some of their failures.

In a perfect world, the law promotes the ecosystem approach and manages the resilience of social ecological systems - such as aquatic ecosystems and their use - in a manner which is sustainable, effective and coherent. An ideal directive should then contain strong goals capable of ensuring the maintenance of desirable ecological resilience, combined with a set of specific exemptions that would allow for striking a fair balance with economic and social resilience - ensuring the overall legitimacy of the design. An alternative design consisting of a broad set of vague or ambiguous goals may not function as effectively, as this design entails a risk that the goals will not be attained at a member state level. The pull of socio-economic goals is often so strong that ecological goals must be overcompensated just to reach a fair balance between the different elements of social ecological resilience. Based on these reflections, we consider the discretion to balance the different substantive goals mentioned in the MSPD as being too broad, not least due to the lack of (m)any enforceable substantive rules. The MSFD is substantively on the right regulatory track, but in our view the WFD contains the most well-balanced system of substantive goals broadened by an exemption system, provided that the criteria for exemptions are not interpreted in a too limiting fashion. Overt formalism looms on the horizon of the WFD's regulatory resilience and adaptive capacity.

From a procedural perspective, all three directives fair rather well. An iterative, science-based, integrated and inclusive planning process of each of the directives is a good starting point for resilient and adaptive regulation. The processes of the WFD and the MSFD are, however, directly linked to the development of science, while the MSPD is not. In addition, although the procedural rules of the MSPD require that member states develop and adapt marine spatial planning practices, the extent to which these practices support the maintenance of ecological resilience might be different from one 
member state to the next, and is not ensured by the directive itself. As aquatic ecosystems are often transboundary in nature, we consider it necessary - in light of ecological resilience - that different member states work towards unified overall goals. Procedurally, the WFD and the MSFD are thus more developed, although the WFD may suffer from its overcomplicated nature. The MSFD, as a matter of regulatory design, is procedurally the most balanced of the three.

From a policy instrument perspective, the WFD and the MSFD contain some economic instruments while the MSPD relies more on direct regulation and voluntary actions at the member state level. Although all three directives are expanding the policy mix towards the outer edges of direct regulation, one of the main problems seems to be the implementation and enforcement of these policy instruments. As a matter of regulatory design, however, the directives illustrate some opportunities for sharing regulatory powers between EU institutions, member states, local actors, and the markets.

Enforceability often requires that environmental goals should be complemented by a set of specific and binding substantive and procedural rules. These rules should facilitate and ensure that member states attain the overall environmental goal(s) of a directive. These rules should be designed in a way which does not unnecessarily complicate national governance approaches (e.g. create overlapping processes geared towards similar substantive goals), or set unrealistic goals or time frames, in order to ensure their effectiveness. Moreover, the rules should be clear and specific enough to be enforceable. The enforceability of both the substantive and procedural rules is an important prerequisite for effectively managing social ecological resilience. At the same time, however, an ideal aquatic directive would contain procedural mechanisms that would allow and force the accumulation of new scientific knowledge to penetrate aquatic planning and management practices. As regards enforceability, the WFD is clearly the strongest of the three.

An ideal directive would also be coherent with already existing directives. This would facilitate its transposition into national laws, and avoid any unnecessary delay in meeting the overall goal of the directive - the social ecological resilience of aquatic systems. Here, the MSFD and the MSPD should have regulatory linkages to the WFD which is the oldest of the three directives. For instance, it would have been expected that the MSPD would have made some references to the WFD, as the MSFD does. If one aims at law promoting the resilience of aquatic social ecological systems and providing a seamless and coherent governance approach to watersheds, coasts and seas, the different directives should at least identify how they interrelate. Even though the European Union officially has no powers regarding land use planning and coastal 
zone management, at a member state level issues of spatial planning in the coastal and marine areas are highly interrelated. For this reason, the coherence of the three directives can still be significantly improved.

Answering the question of what kind of governance and regulation should be used to safeguard the core functions of social ecological systems is no walk in the park. First, this is so because of the different aquatic media having environmental problems somewhat particular to each media, as well as particular sectors and uses that are causing these problems. Second, the walk is obstructed by the lack of empirical analysis generally - and in this chapter specifically - regarding the functionality of existing regulatory instruments. Our analysis here will have to be complemented in the future by a more empirically oriented analysis to see whether the potential triumphs and failures of the directives actualise. Nevertheless, it makes sense to anticipate regulatory failures and respond to them where possible as the regulation or management of aquatic environments cannot wait for perfect science. Regulatory designs must keep this in mind, and embrace experimental and adaptive governance, without abandoning the rule of law and legal certainty. Law's resilience and adaptive capacity is a careful combination of all these criteria.

\section{Table of Authorities}

\section{Treaties}

Convention on Biological Diversity (adopted 22 May 1992, entered into force 29 December 1993, 1760 UNTS 79).

Convention on Biological Diversity, Conference of the Parties 5 Decision v/6 'Ecosystem Approach' 2000, (22 June 2000) UNEP/CBD/COP/5/23.

\section{EU Legislation}

Council Directive 92/43/EEC of 21 May 1992 on the conservation of natural habitats and of wild fauna and flora [1992] OJ L206/7.

Council Directive 2000/60/EC of 22 December 2000 establishing a framework for Community action in the field of water policy [2002] OJ L $327 / 22$.

Council Directive 2008/56/EC of 17 June 2008 establishing a framework for community action in the field of marine environmental policy [2008] OJ L164/19.

Council Directive 2009/147/EC of the European Parliament and of the Council of 30 November 2009 on the conservation of wild birds [2009] OJ L 20/7.

Council Directive 2014/89/EU of 23 July 2014 establishing a framework for maritime spatial planning [2014] OJ L257/135. 


\section{Cases}

Case 237/07, Dieter Janecekv Freistaat Bayern [2008] ECLI:EU:C:2008:447.

Case 525/12, European Commission v Federal Republic of Germany [2014] ECLI:EU:C:2014:2202.

Case 461/13, Bund für Umwelt und Naturschutz Deutschland eV v Bundesrepublik Deutschland [2015] ECLI:EU:C:2015: 433.

\section{Bibliography}

\section{Books}

Bohman B, Transboundary Law for Social-Ecological Resilience. A Study on Eutrophication in the Baltic Sea (Stockholm University 2017).

Clayton AMH and Radcliffe NJ, Sustainability: A Systems Approach (Routledge 1996).

Hart HLA, The Concept of Law (2nd edition, Oxford University Press 1994).

Holling CS, Adaptive Environmental Assessment and Management (John Wiley and Sons 1978).

Pasteur K, From Vulnerability to Resilience. A framework for analysis and action to build community resilience (Practical Action Publishing 2011).

Platjouw FM, Environmental law and the ecosystem approach: Maintaining ecological integrity through consistency in law (Routledge 2016).

Walters CJ, Adaptive Management of Renewable Resources (Macmillan 1986).

\section{Official Documents and Others}

European Commission, 'Common Implementation Strategy for the Water Framework Directive (2000/6o/EC). Guidance document no. 8 Public Participation in relation to the Water Framework Directive (Office for Official Publications 2003).

European Commission, 'Proposal for a Directive of the European Parliament and of the Council establishing a framework for Community Action in the Field of Marine Environmental Policy (Marine Strategy Directive)' (Communication) сом (2005) 505 final.

European Commission, 'An Integrated Maritime Policy for the European Union' (Blue Paper) сом (2007) 574 final.

European Commission, 'Action Plan on an EU Integrated Maritime Policy' SEC (2007) 575 final.

European Commission, 'Roadmap for Maritime Spatial Planning: Achieving Common principles in the EU' Сом (2008) 791 final.

European Commission, 'Maritime Spatial Planning in the EU - Achievements and future development' сом (2010) 771 . 
European Parliament legislative resolution of 17 April 2014 on the proposal for a directive of the European Parliament and of the Council establishing a framework for maritime spatial planning and integrated coastal maritime spatial planning and integrated coastal management' СОМ (2013) 0133 .

Farmer AM and others, KnowSeas. Knowledge-based Sustainable Management for Europe's Regional Seas. The Ecosystem Approach in Marine Management (EU FP7 KnowSeas Project 2012).

HelCom, Eutrophication status of the Baltic Sea 2007-2011 - A concise thematic assessment (Baltic Sea Environment Proceedings No. 143, HELCOM 2014) 5-6.

Helcom, Ecosystem Health of the Baltic Sea. нецcom Initial Holistic Assessment (Baltic Sea Environment Proceedings No. 122, 2010).

House of Lords Committee, European Union Committee, 'The North Sea under pressure: is regional marine co-operation the answer?' (1oth Report of Session 2014-15, House of Lords paper 137, 2015).

Intergovernmental panel on climate change, Climate Change 2007: Impacts, Adaptation and Vulnerability (Contribution of Working Group II to the Fourth Assessment Report of the Intergovernmental Panel on Climate Change, Cambridge University Press 2007).

Programme of measures of the Finnish marine strategy 2016-2021, $4<$ http://www .ymparisto.fi/en-US/Sea/Protection_and_management_of_the_marine_ environment/Development_of_Finlands_marine_strategy> accessed 20 September 2017.

United Nations Environment Programme, Millennium Ecosystem Assessment, Living Beyond Our Means. Natural Assets and Human Well-being. Statement of the MA Board (Island Press 2005).

UN Water (2017) Water, Food and Energy <http://www.unwater.org/water-facts/waterfood-and-energy/> accessed 22 September 2017.

\section{Book Chapters}

Belinskij A, 'Recovery of costs for water uses at the different levels of water law' in E Hollo (ed), Water Resource Management and the Law (Edward Elgar 2017) 213.

Bugge HC, Twelve Fundamental Challenges in Environmental Law, in C Voigt (ed), Rule of Law for Nature. New Dimensions and Ideas in Environmental Law (Cambridge University Press 2013) 3.

Groothuijse F and Uylenburg R, 'Everything according to plan? Achieving environmental quality standards by a programmatic approach' in M Peeters and R Uylenburg (eds), EU Environmental Legislation - Legal Perspectives on Regulatory Strategies (Edward Elgar Publishing 2014) 116.

Jonsson B and Jonsson N, 'Fennoscandian freshwater fisheries: diversity, use, threats and management' in JF Craig (ed), Freshwater Fisheries Ecology (Wiley Blackwell 2016) 105 . 
Soininen N, 'Torn by (un)certainty - Can there be peace between rule of law and other SDGs?' in D French and L Kotzé (eds), Sustainable Development Goals: Law, Theory \& Implementation (Edward Elgar 2018).

Soininen, N 'Marine spatial planning in the European Union' in D Hassan, T Kuokkanen and N Soininen (eds), Transboundary Marine Spatial Planning and International Law (Routledge/Earthscan 2015).

\section{Journal Articles}

Arnold GA and Gunderson LH, 'Adaptive Law and Resilience' (2013) 43 Environmental Law Reporter 10426.

Backer H, 'Trans-boundary Maritime Spatial Planning: a Baltic Sea Perspective' (2011) 15 Journal of Coastal Conservation 279.

Belinskij A and Soininen N, 'Bringing back ecological flows: The case of migratory fish and the Regulation of Hydropower in Finland' (2017) X Ympäristöpolitiikan ja oikeuden vuosikirja 89 (in Finnish).

Benson MH, 'Integrating Adaptive Management and Oil and Gas Development: Existing Obstacles and Opportunities for Reform' (2009) 39 Environmental Law Reporter 10962.

Biber E and Eagle J, 'When Does Legal Flexibility Work in Environmental Law?' (2015) 42 Ecology Law Quarterly 787.

Borja A and others, 'Overview of Integrative Assessment of Marine Systems: The Ecosystem Approach in Practice' (2016) 3 Frontiers in Marine Science.

Camacho AE and Glicksman RL, 'Legal Adaptive Capacity: How Program Goals and Processes Shape Federal Land Adaptation to Climate Change' (2016) 87(3) University of Colorado Law Review 711.

Cosens B, 'Transboundary River Governance in the Face of Uncertainty: Resilience Theory and the Columbia River Treaty' (2010) 30(2) Journal of Land Resources and Environmental Law 229.

Craig RK, "Stationarity Is Dead" - Long Live Transformation: Five Principles for Climate Change Adaptation Law' (2010) 34 Harvard Environmental Law Review 9.

De Lucia V, 'Competing Narratives and Complex Genealogies: The Ecosystem Approach in International Environmental Law' (2014) 27 Journal of Environmental Law 91.

Ebbesson J, 'The rule of law in governance of complex socio-ecological changes' (2010) 20 Global Environmental Change (3) 414.

Grizzetti B and others, 'Assessing water ecosystem services for water resource management' (2016) 61 Environmental Science and Policy 194.

Keessen AM and van Rijswick HFMW, 'Adaptation to Climate Change in European Water Law and Policy' (2012) 8(3) Utrecht Law Review 38.

McDonald J and Styles MC, 'Legal Strategies for Adaptive Management under Climate Change' (2014) 26 Journal of Environmental Law 25. 
Olszynski M, 'Failed Experiments: An Empirical Assessment of Adaptive Management in Alberta's Energy Resources Sector' (2017) 50 University of British Columbia Law Review 697.

Paganelli D and others, 'Critical appraisal on the identification of Reference Conditions for the evaluation of ecological quality status along the Emilia-Romagna coast (Italy) using M-AMBI' (2011) 62(8) Marine Pollution Bulletin 1725.

Paloniitty T, 'The Weser Case: Case C-461/13 BUND V GERMANY' (2016) 28(1) Journal of Environmental Law 151.

Pardy B, 'Changing Nature: The Myth of the Inevitability of Ecosystem Management' (2003) 20 Pace Environmental Law Review 675.

Pardy B, 'The Pardy-Ruhl Dialogue on Ecosystem Management Part V: Discretion, Complex-Adaptive Problem Solving and the Rule of Law' (2008) 25 Pace Environmental Law Review 341.

Platjouw FM, 'Transboundary marine spatial planning in the North Sea - Are national policies and legal structures compatible enough? The case of Norway and the Netherlands' (2018) 33(1) International Journal of Marine and Coastal Law 34.

Redman C, Grove MJ and Kuby L, 'Integrating Social Science into the Long Term Ecological Research (LTER) Network: Social Dimensions of Ecological Change and Ecological Dimensions of Social Change' (2014) 7 Ecosystems 161.

Rist L and others, 'A New Paradigm for Adaptive Management' (2013) 18(4) Ecology \& Society 63 .

Rist L, Campbell BM and Frost P, 'Adaptive management: where are we now?' (2012) 40(1) Environmental Conservation 5.

Ruhl JB, 'General Design Principles for Resilience and Adaptive Capacity in Legal Systems - With Applications to Climate Change Adaptation' (2011) 89 North Carolina Law Review 1373 .

Ruhl JB, 'The Myth of What is Inevitable Under Ecosystem Management: A Response to Pardy' (2004) 21 Pace Environmental Law Review 315.

Ruhl JB, 'Thinking of Environmental Law as a Complex Adaptive System: How to Clean Up the Environment by Making a Mess of Environmental Law' (1997) 34 Houston Law Review 101.

Schoukens H, 'Ongoing activities and Natura 2000 Biodiversity Protection vs Legitimate Expectations?' (2014) 11 Journal for European Environmental \& Planning Law 1.

Squintani L and van Rijswick H, 'Improving Legal Certainty and Adaptability in the Programmatic Approach' (2016) 28 Journal of Environmental Law 443.

Waldron J, 'The concept and the Rule of Law' (2008) 43 Georgia Law Review 1.

Walker B and others, 'A Handful of Heuristics and Some Propositions for Understanding Resilience in Social-Ecological Systems' (2006) 11 Ecology \& Society 13.

Williams BK, 'Passive and active adaptive management: Approaches and an example' (2011) 92 Journal of Environmental Management 1371. 


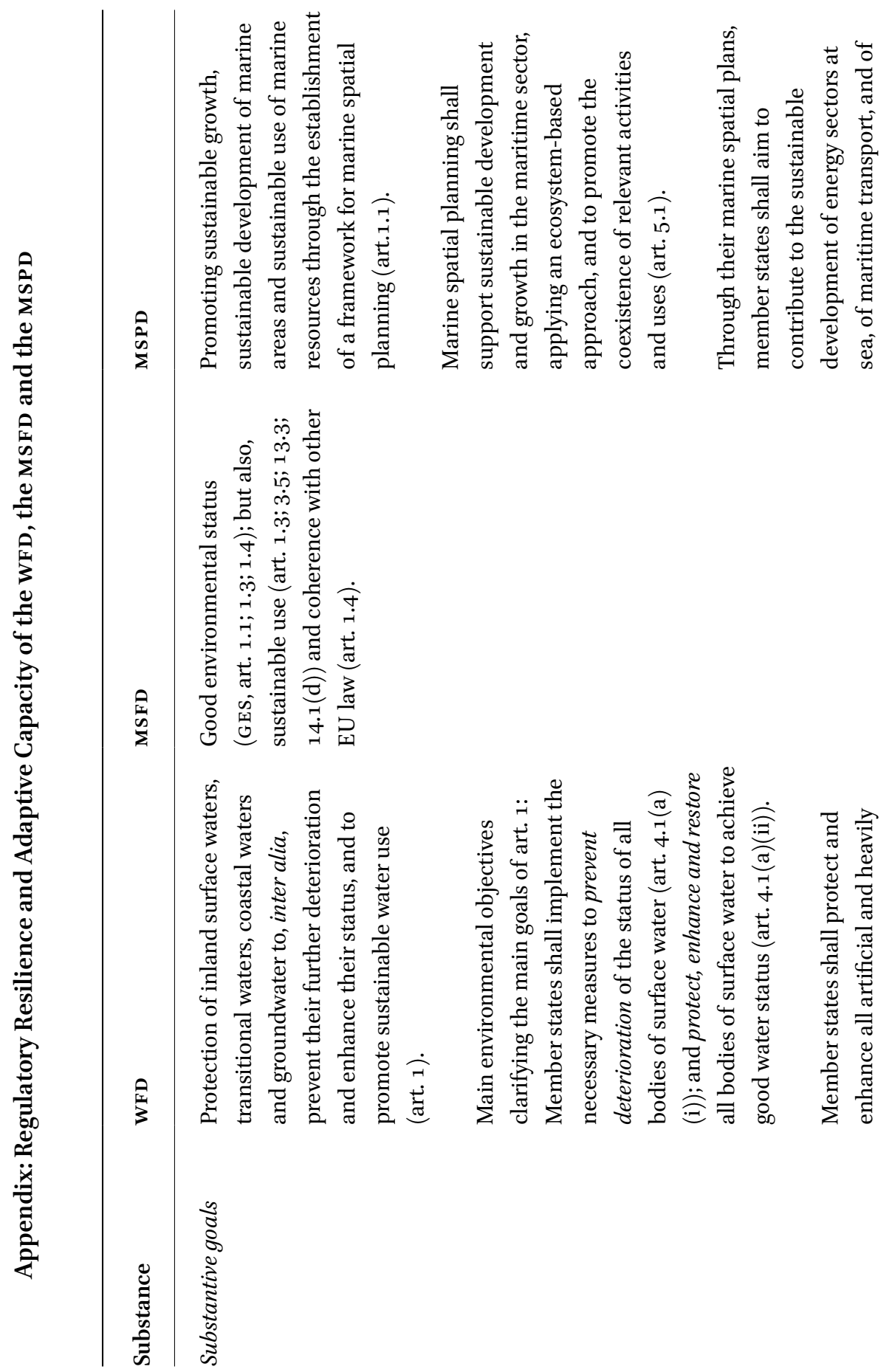




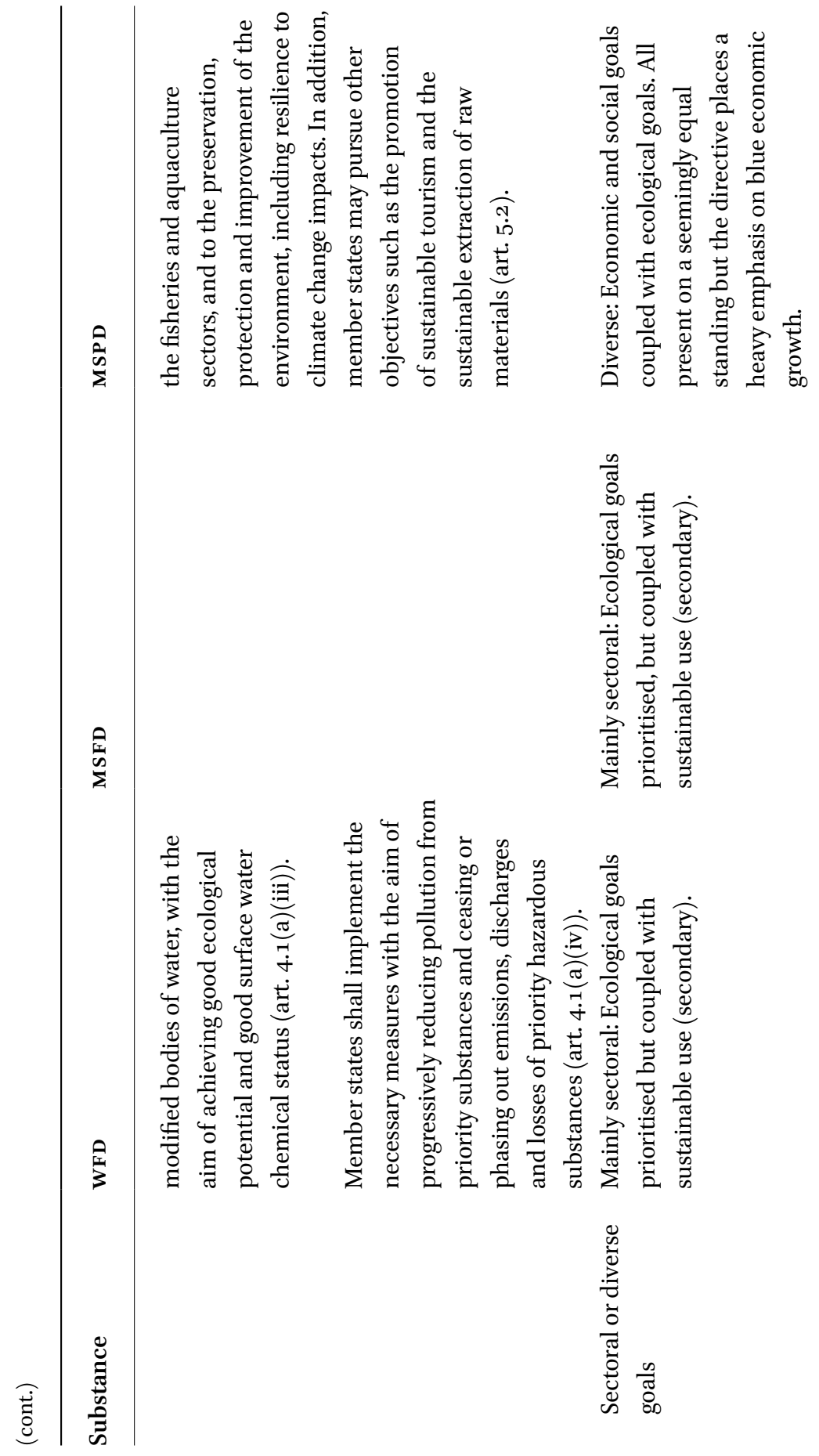




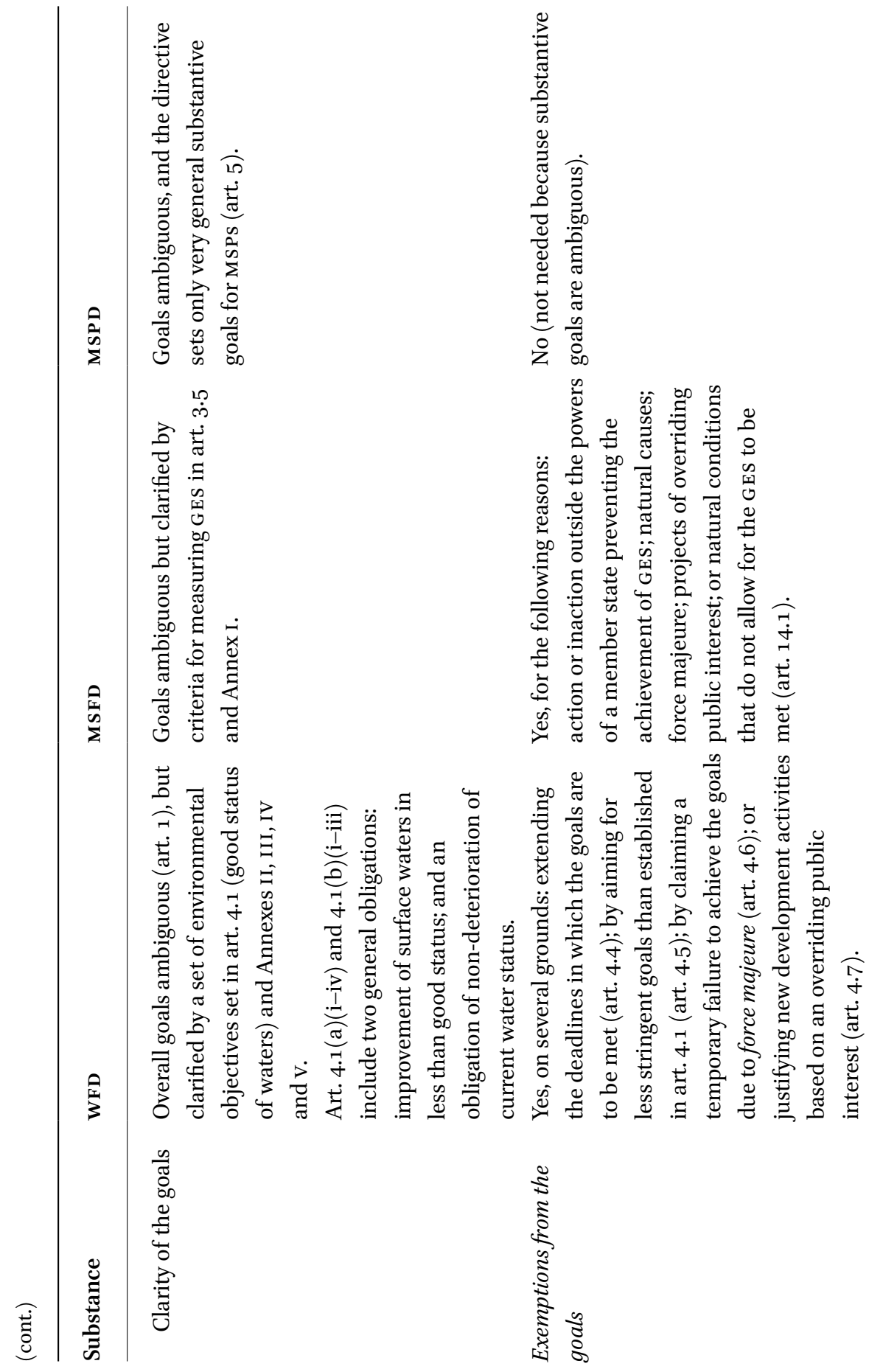




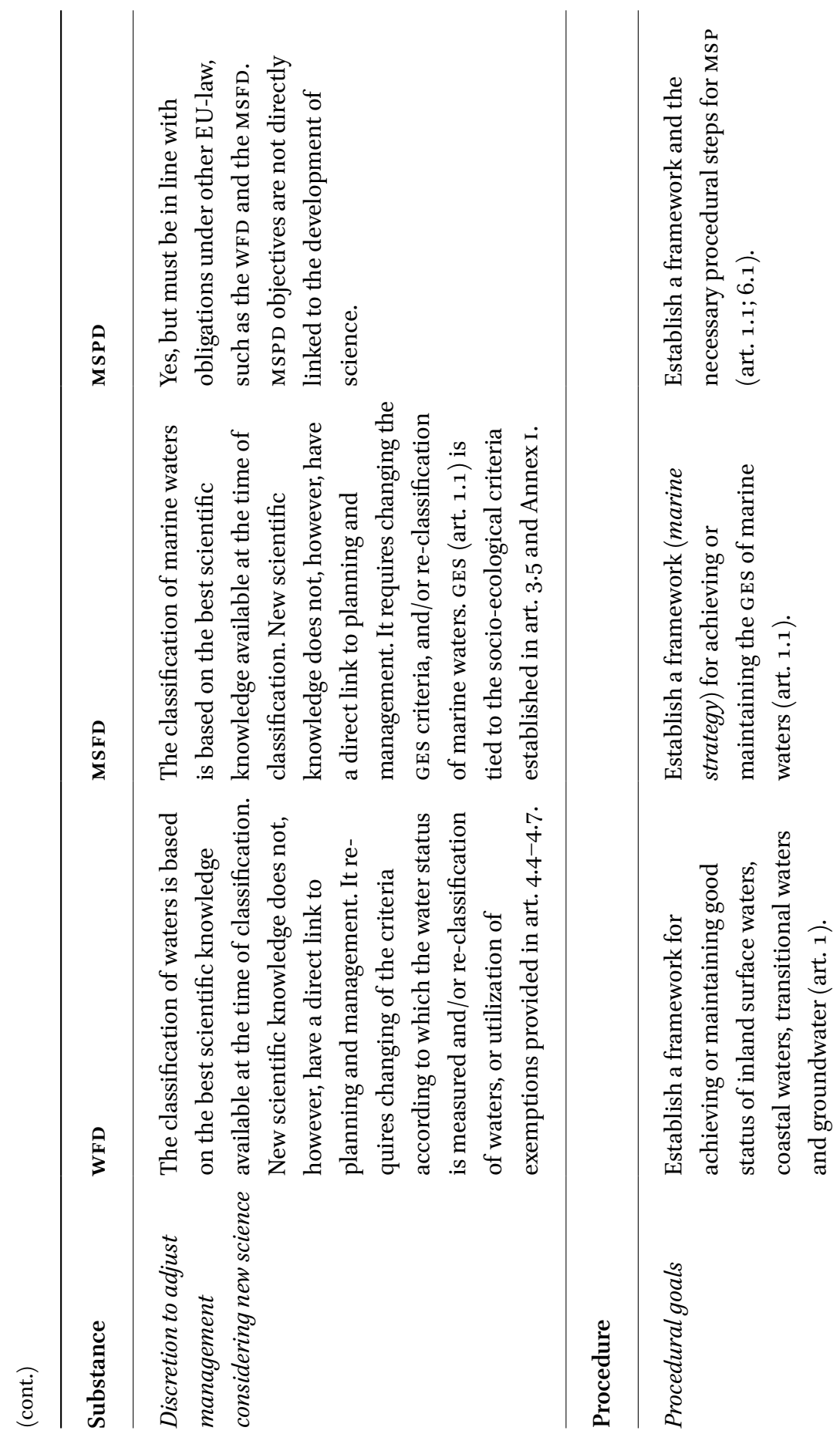




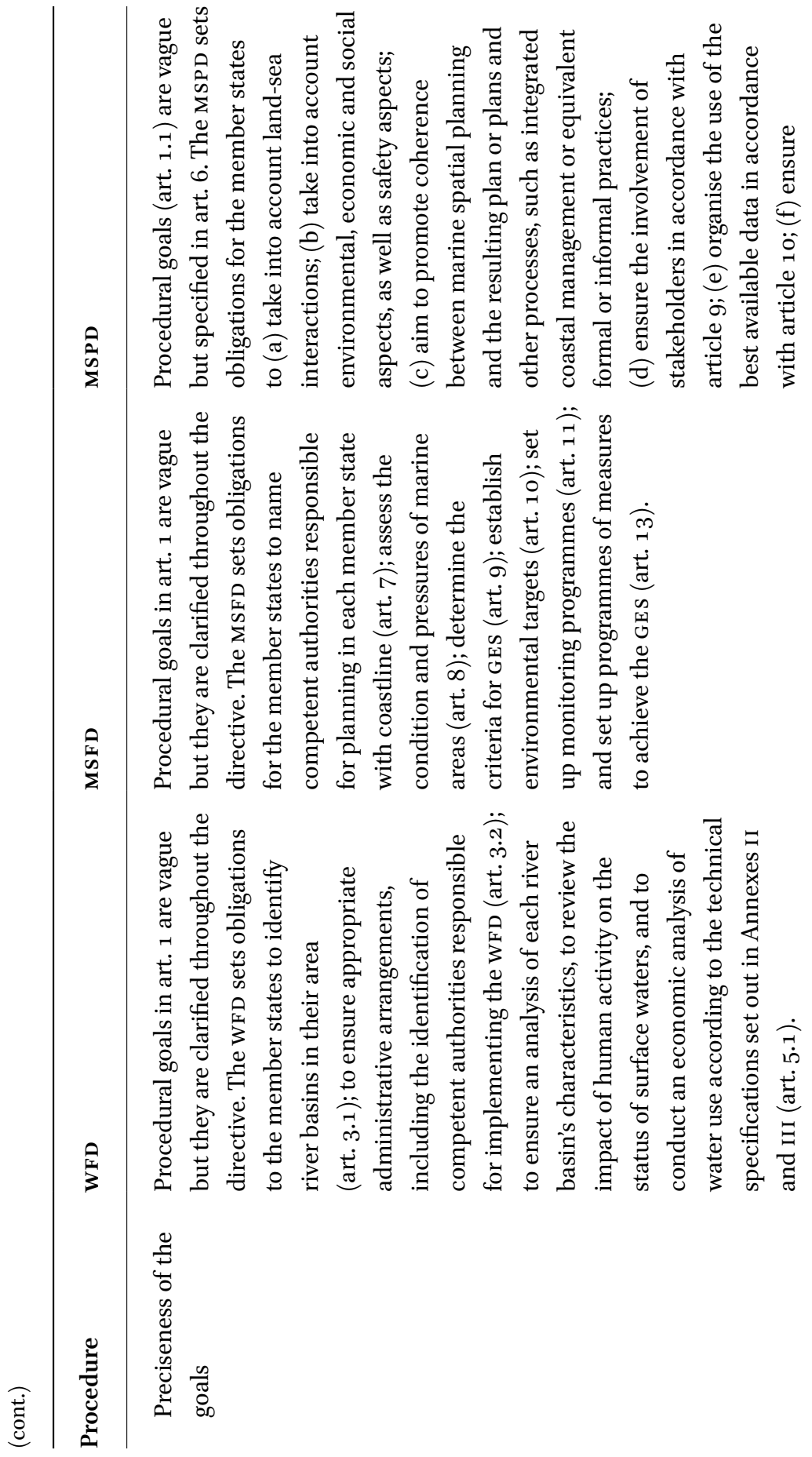




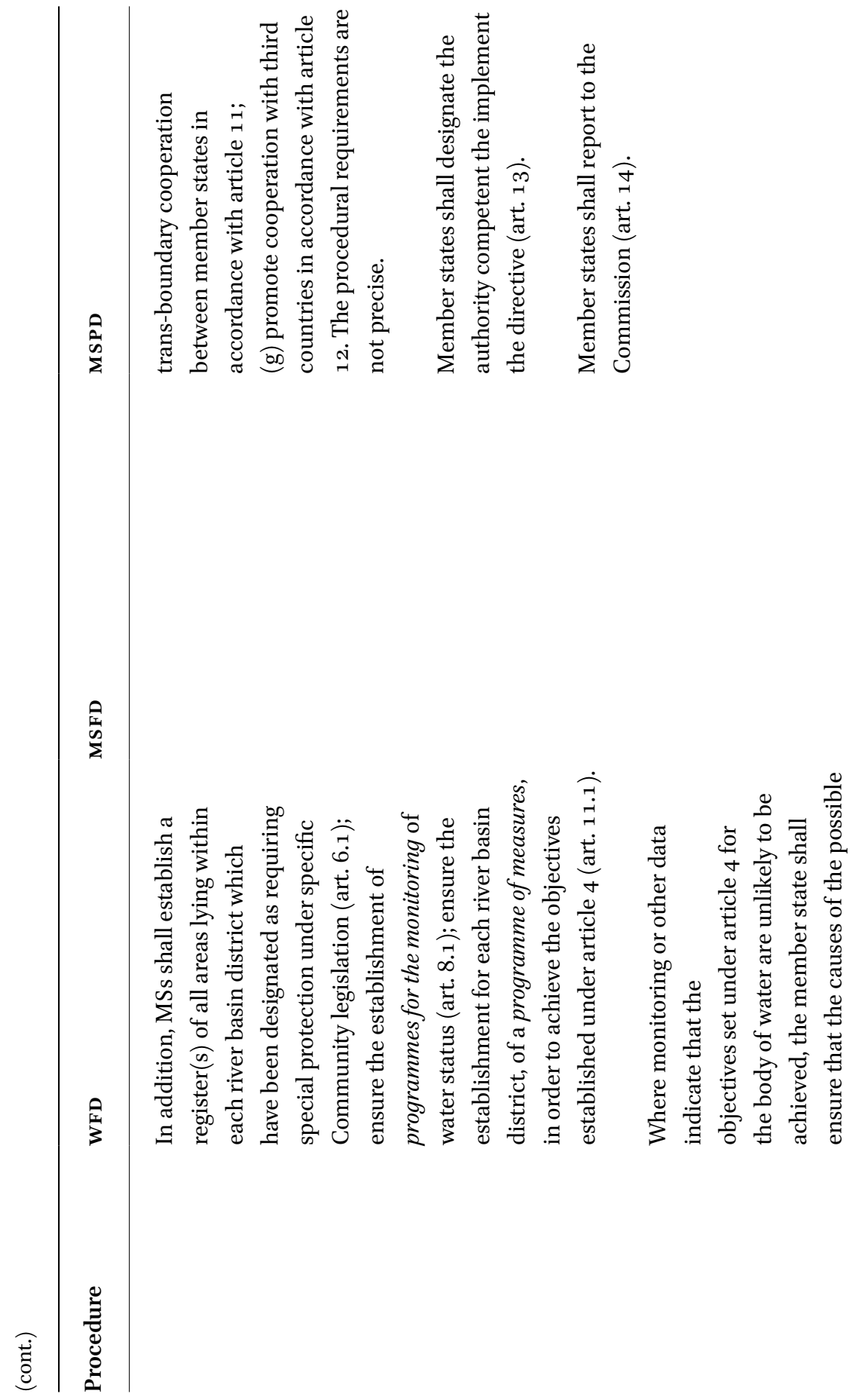




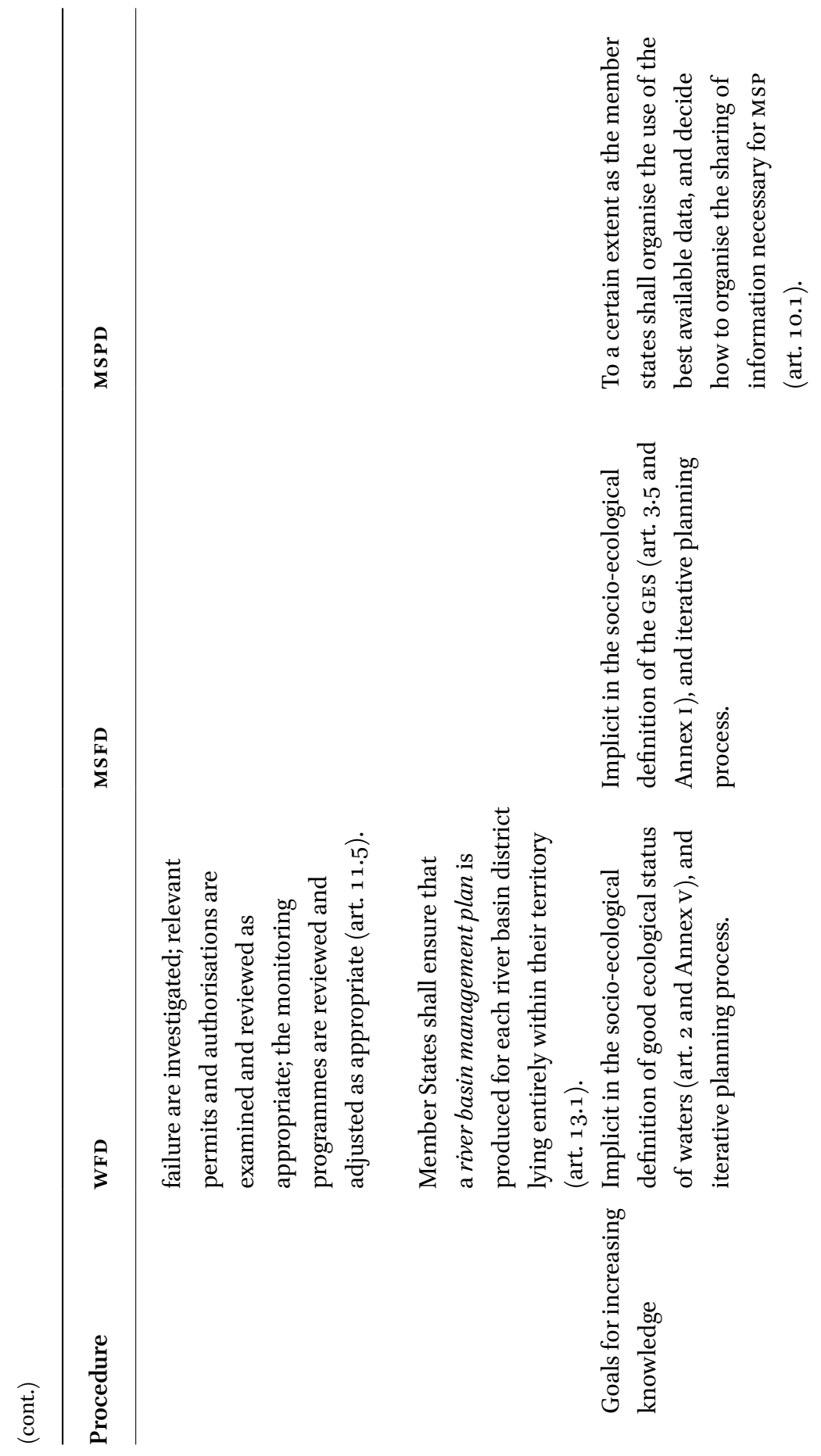




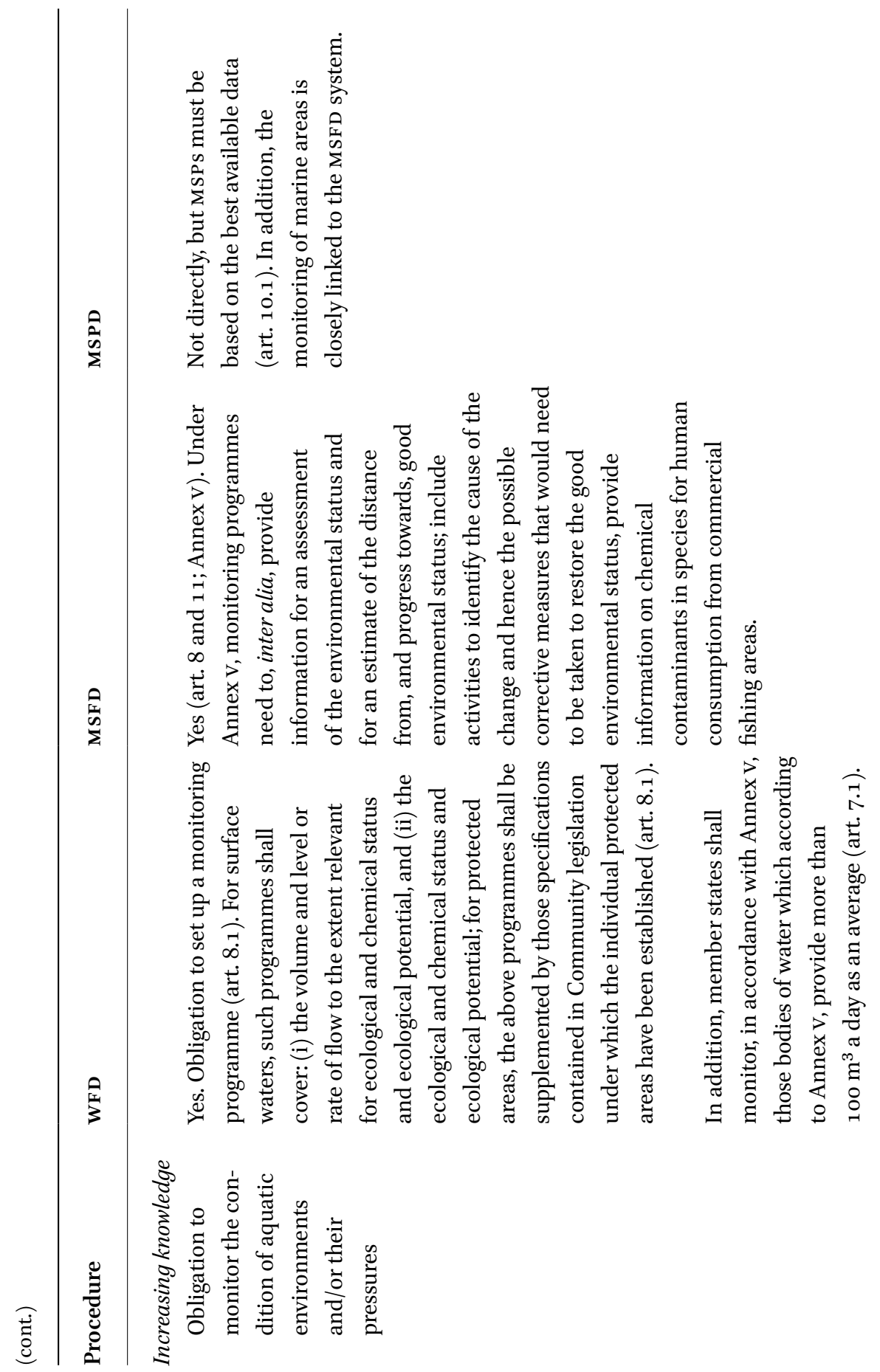




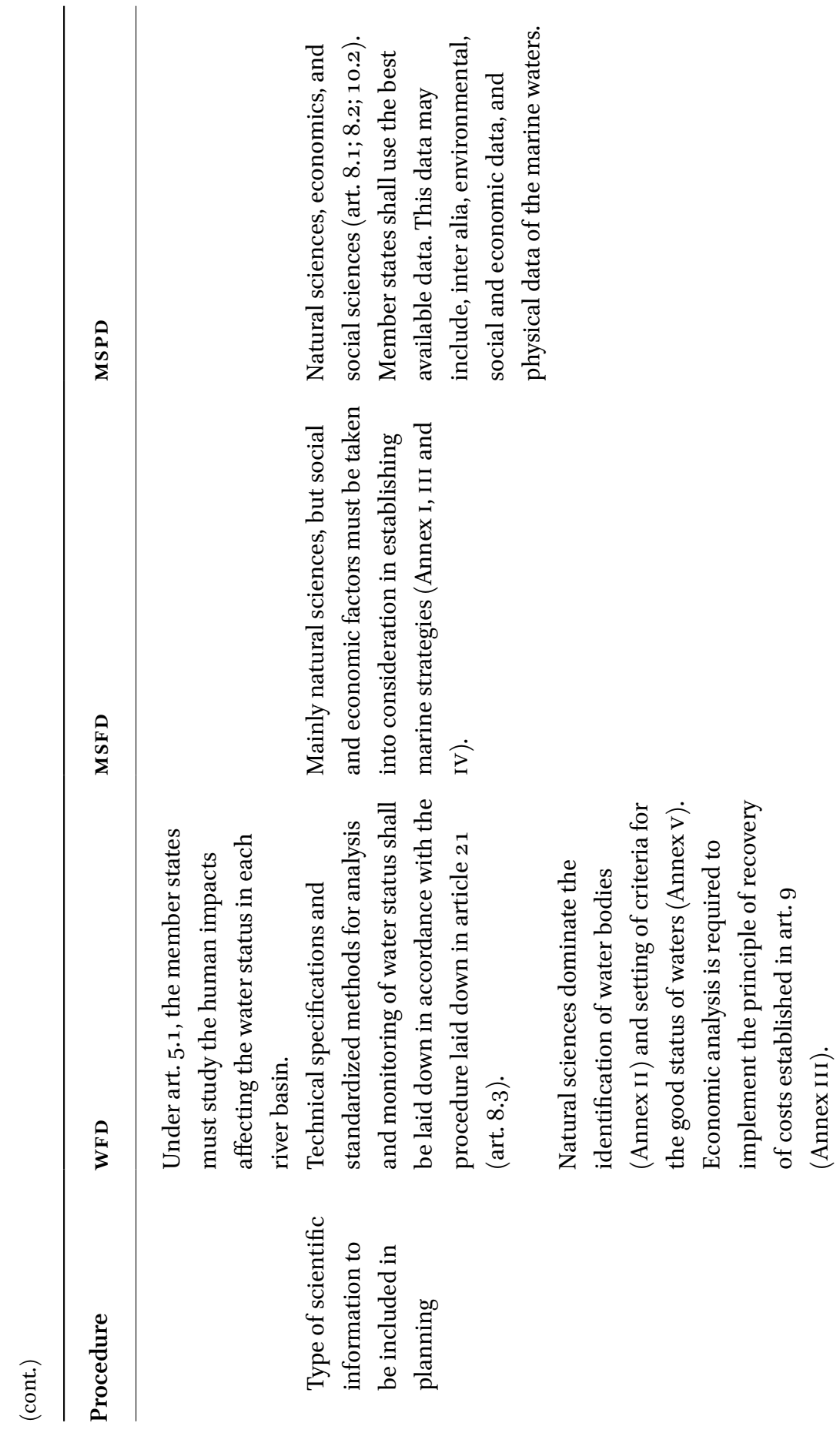




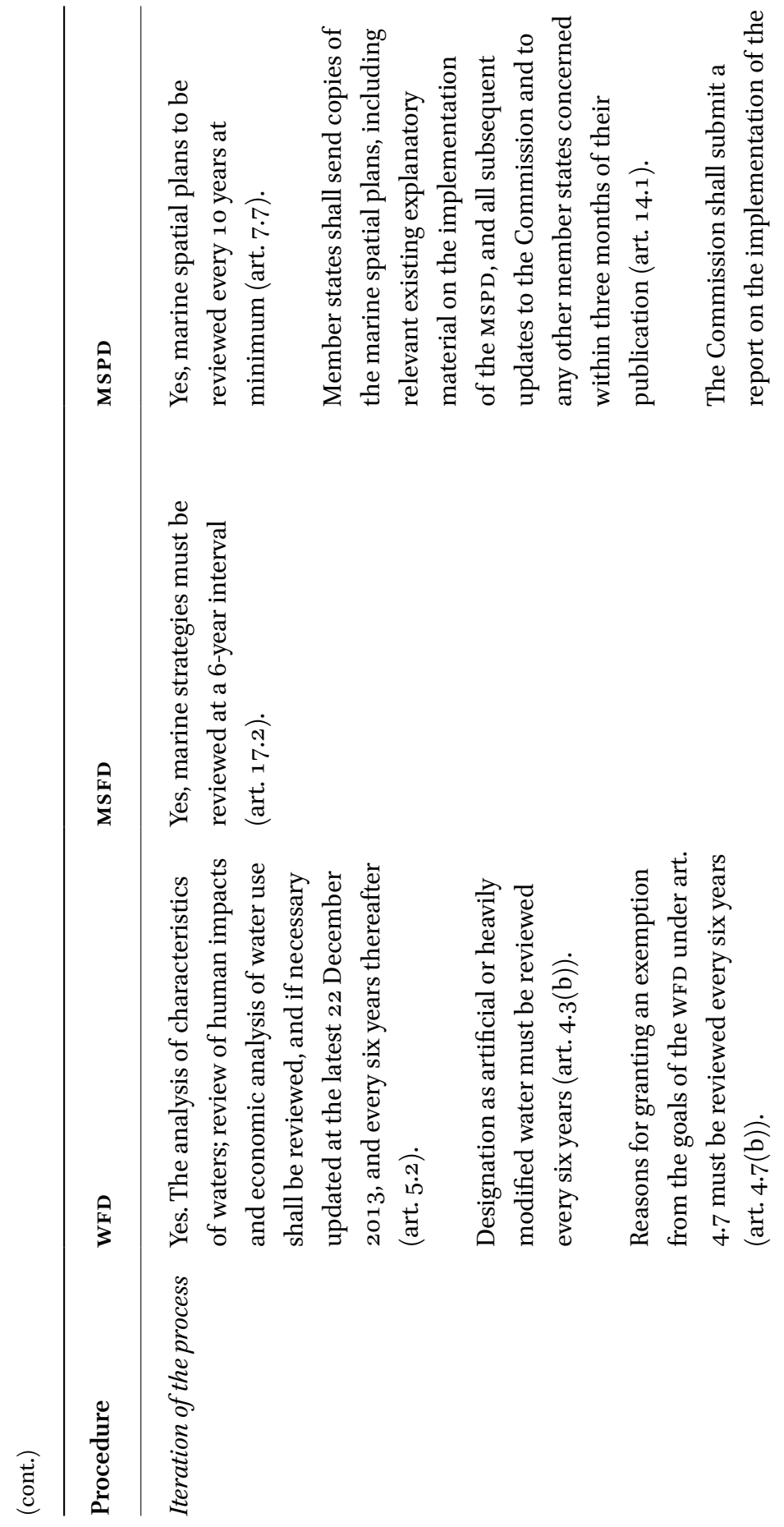




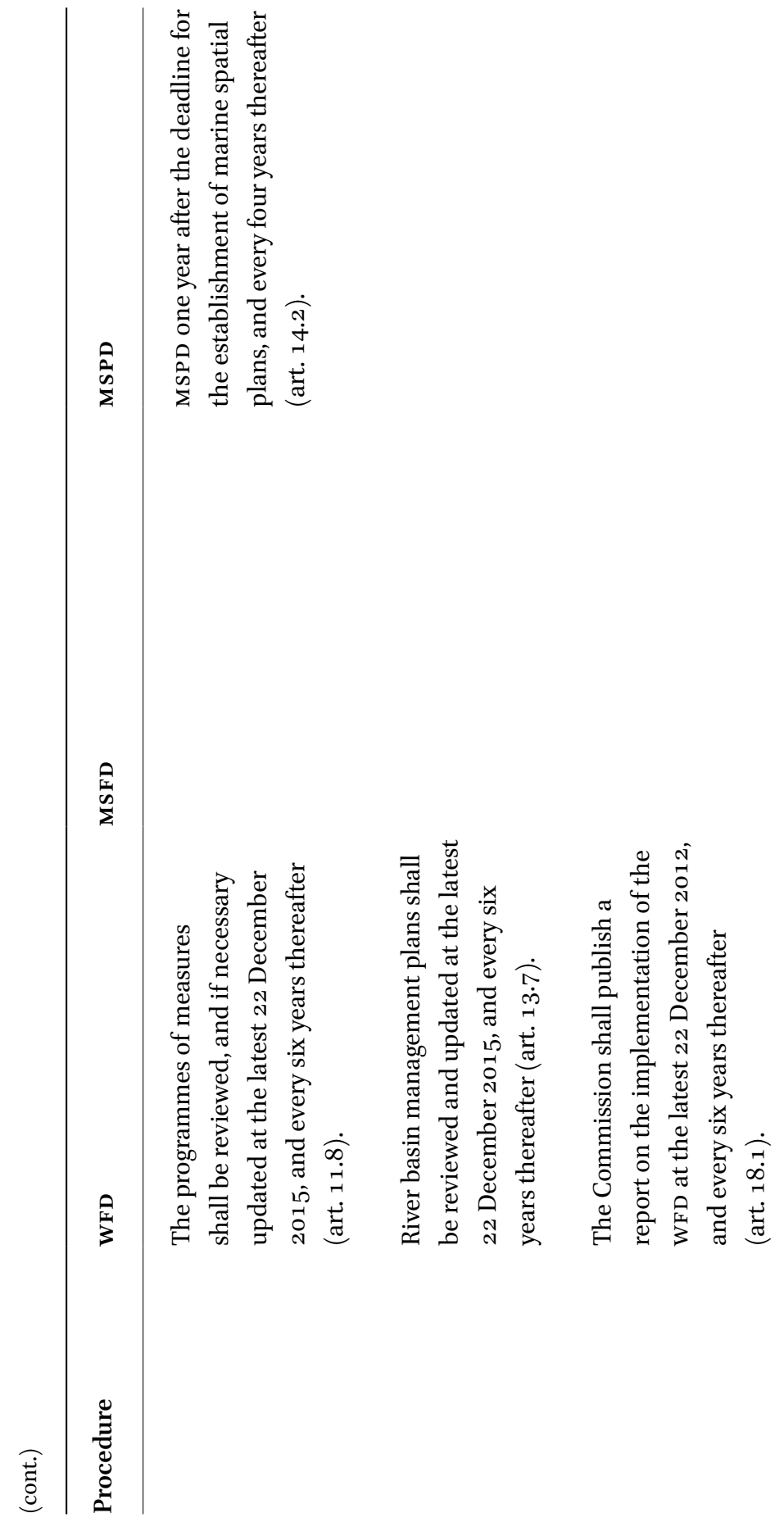




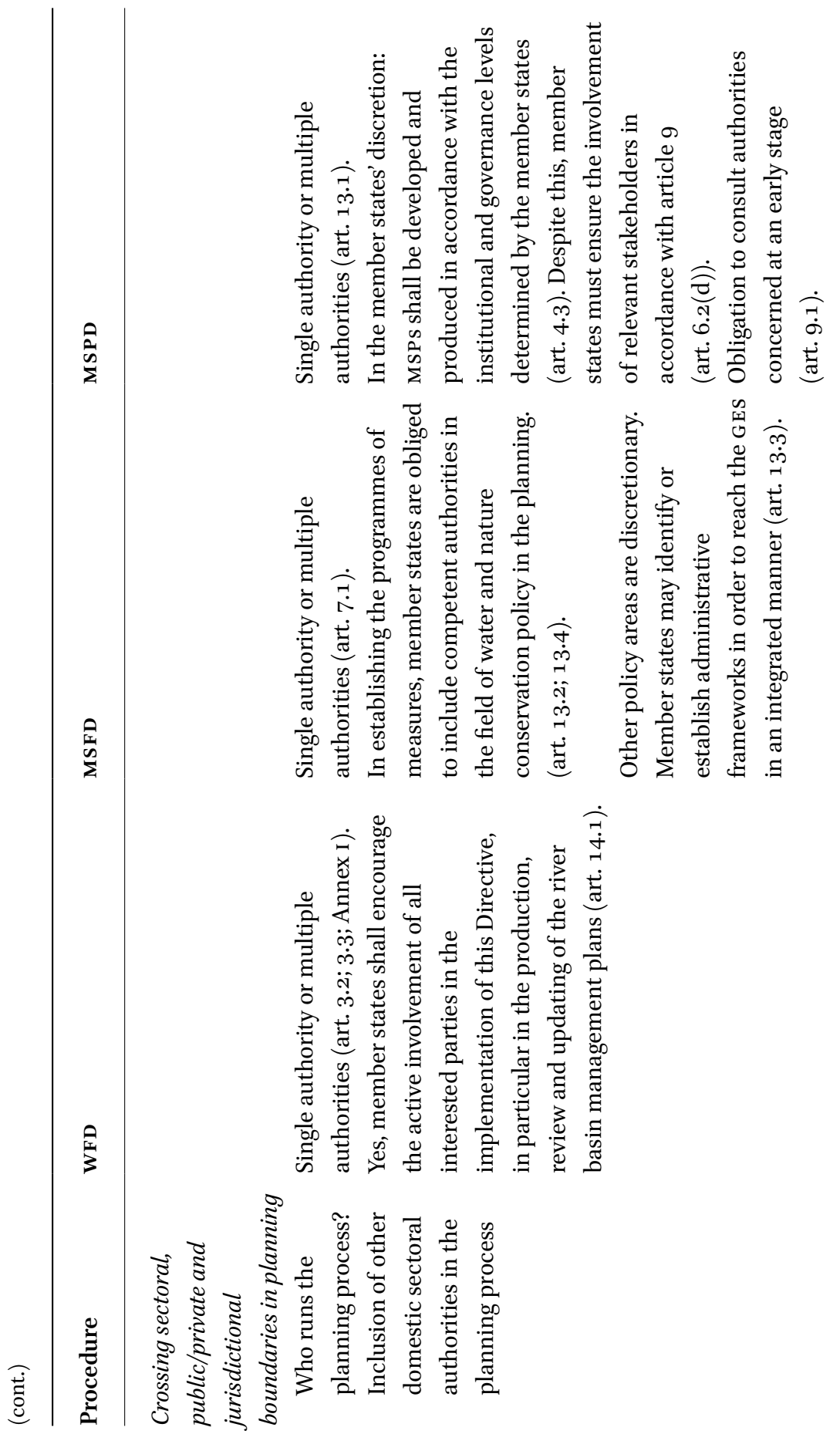




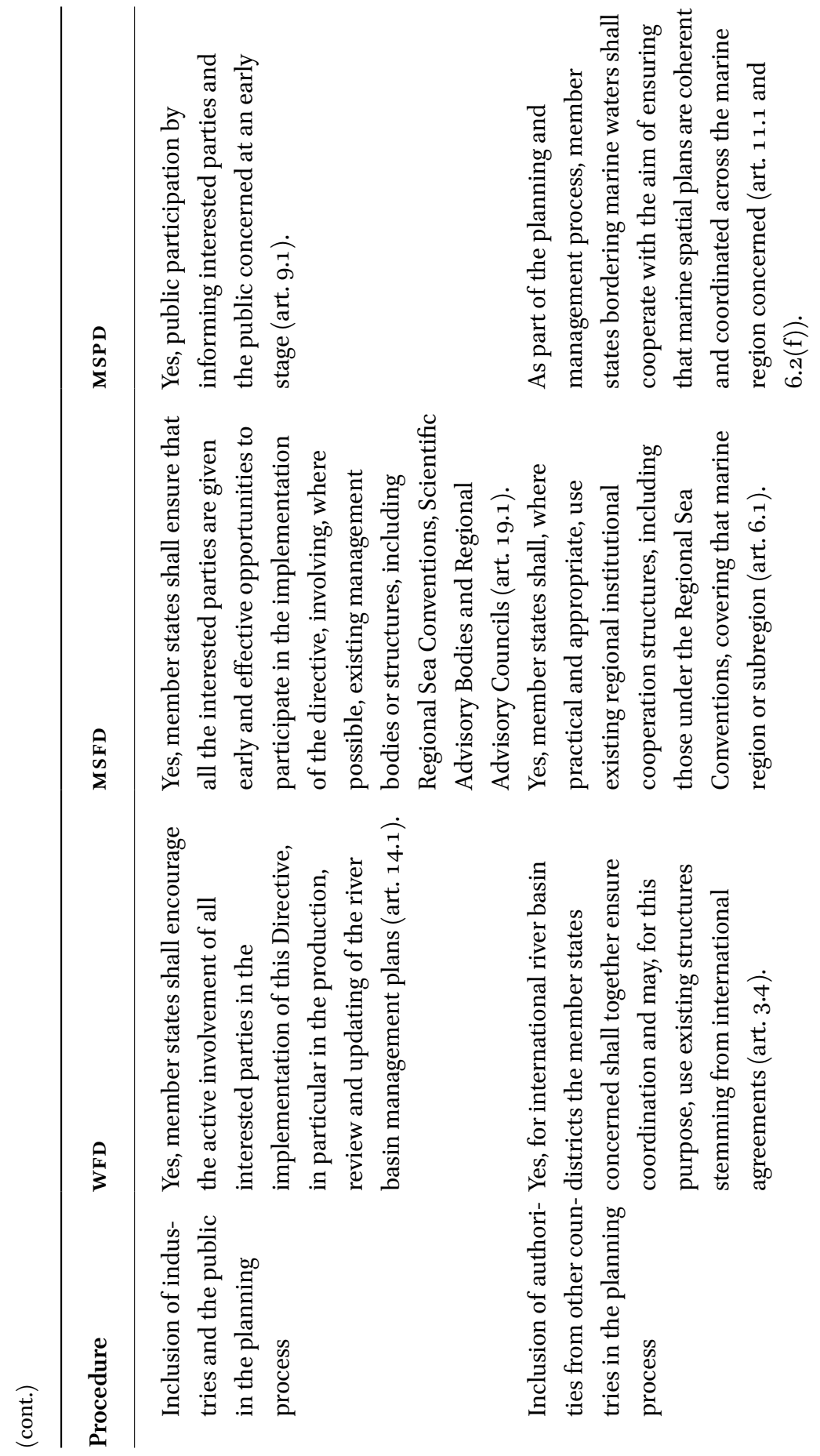




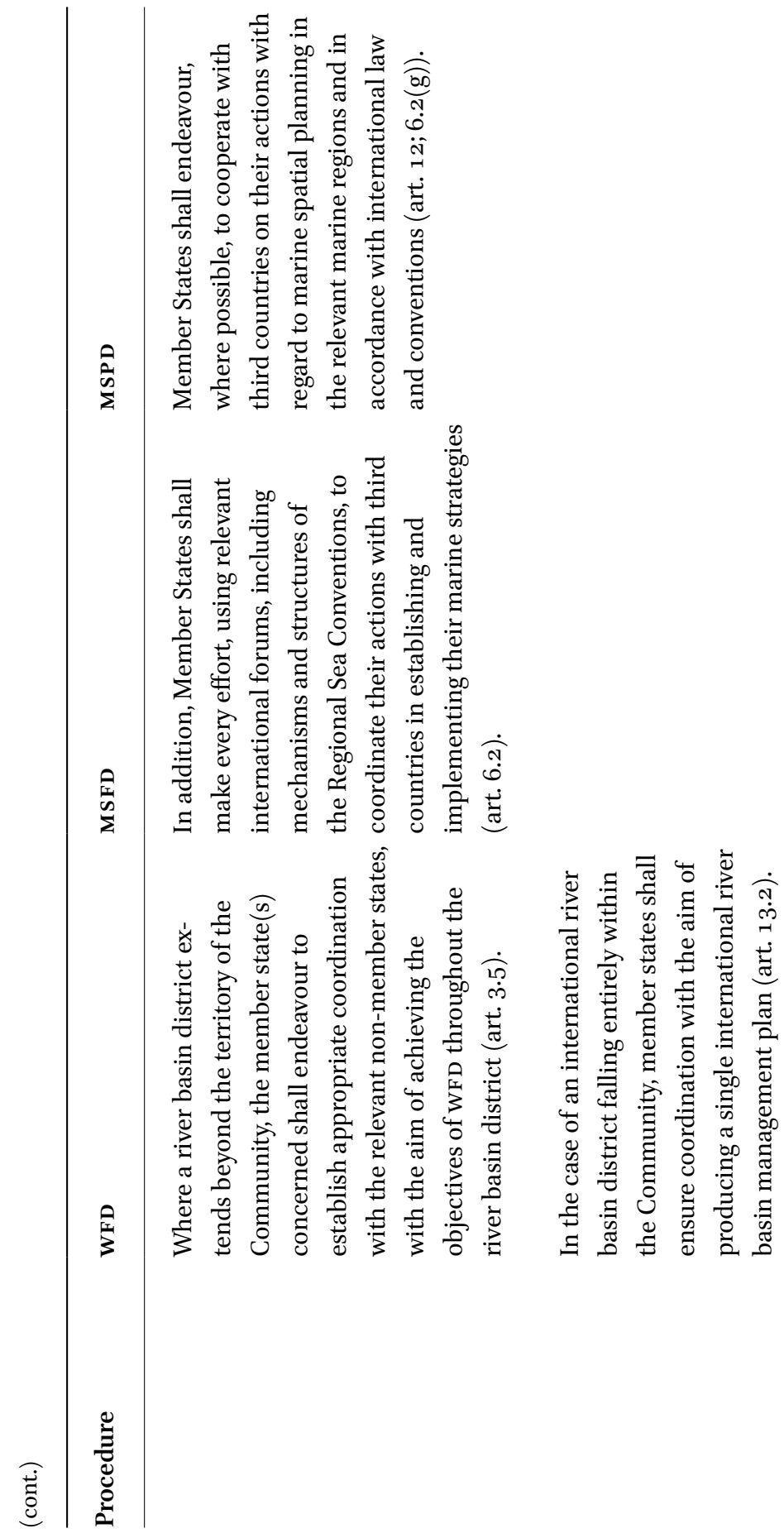




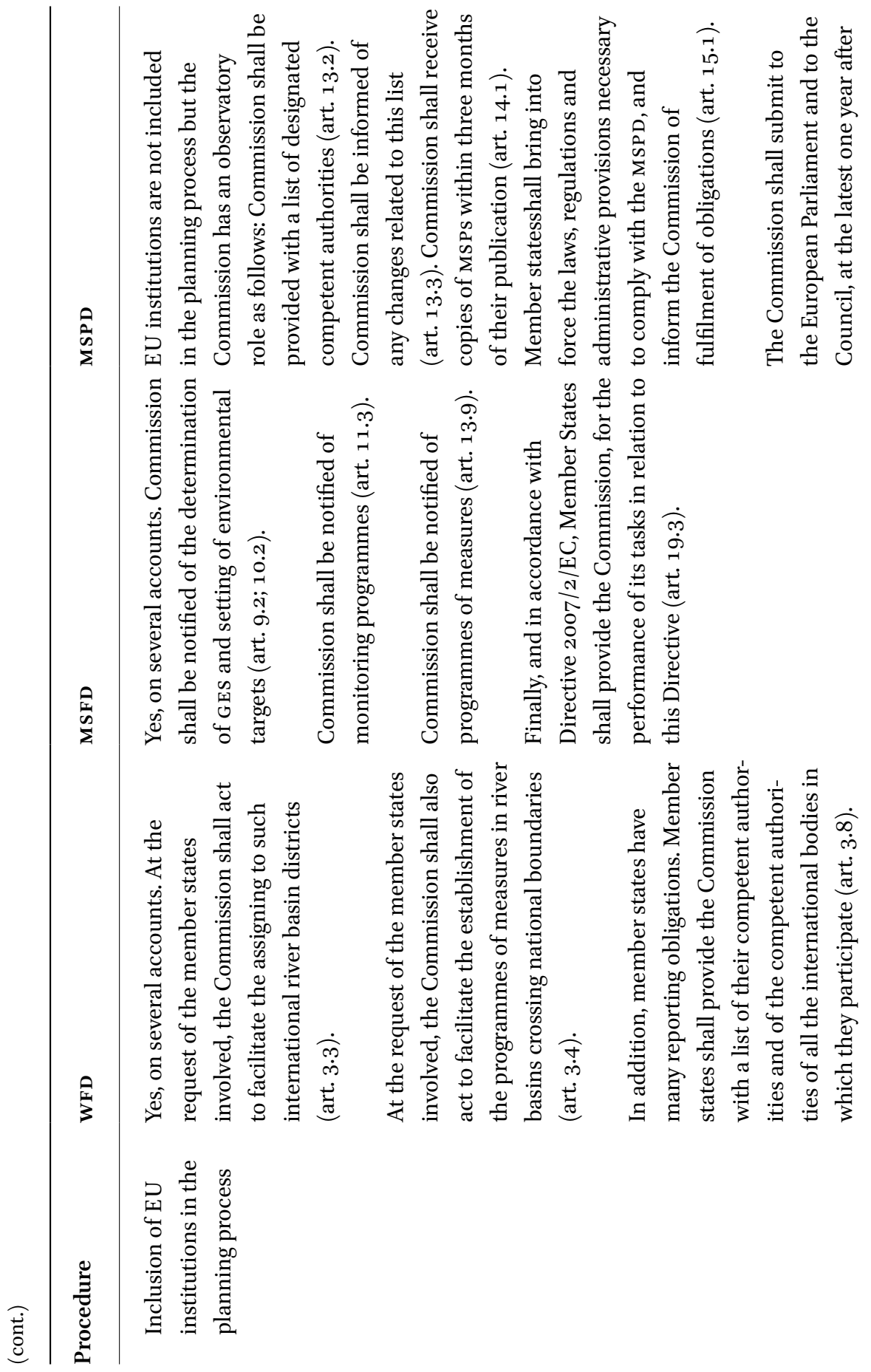




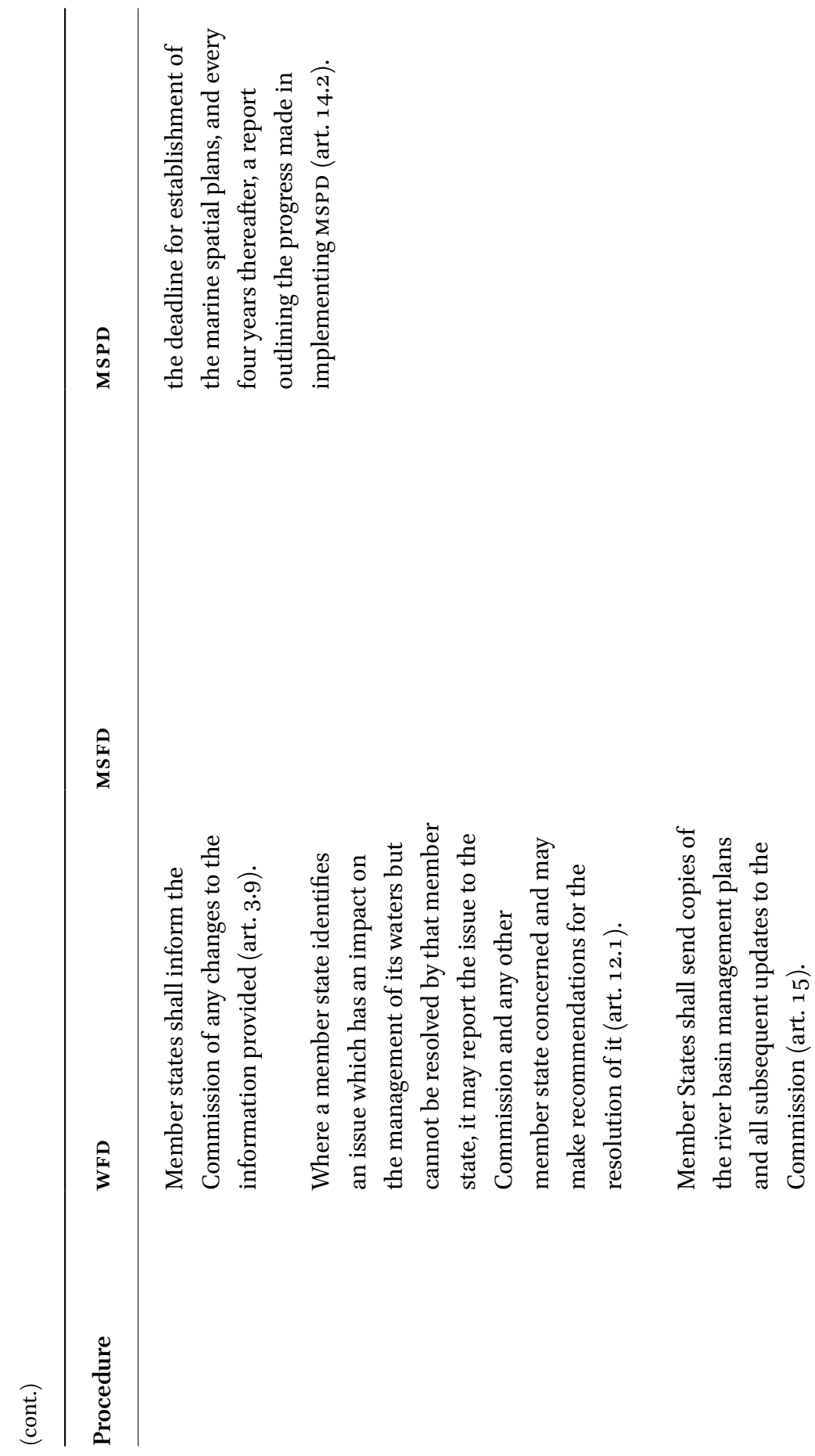




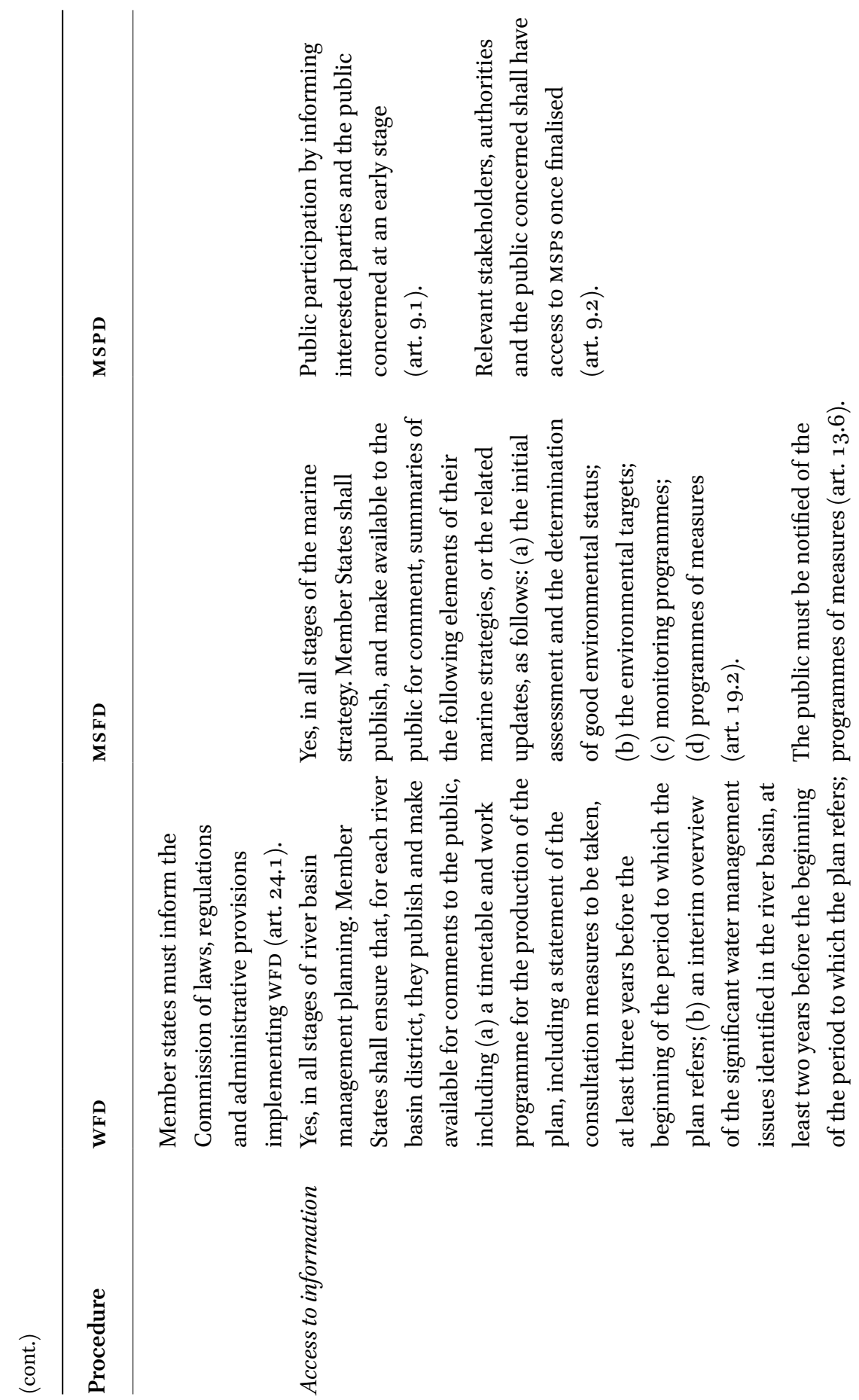




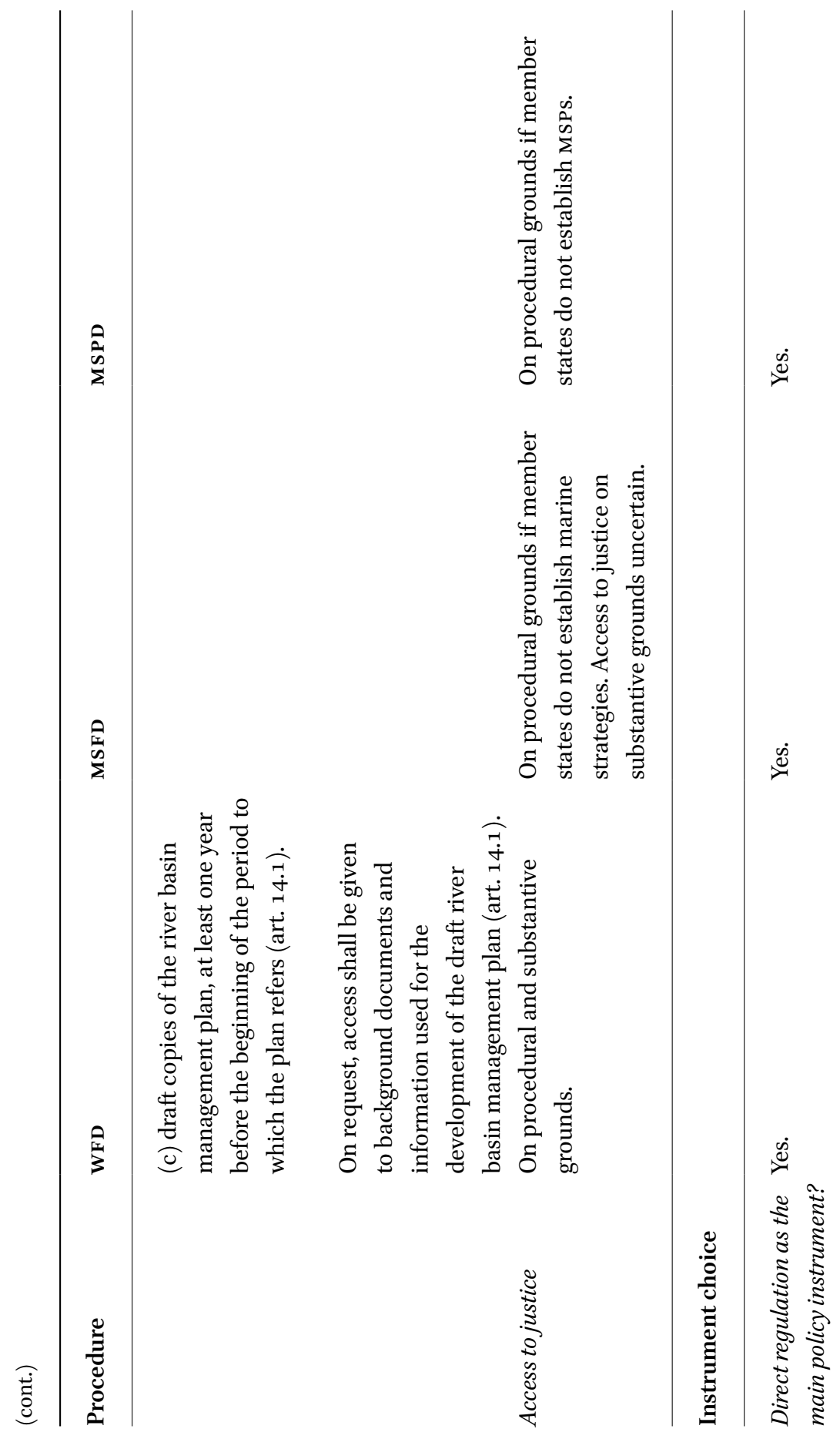




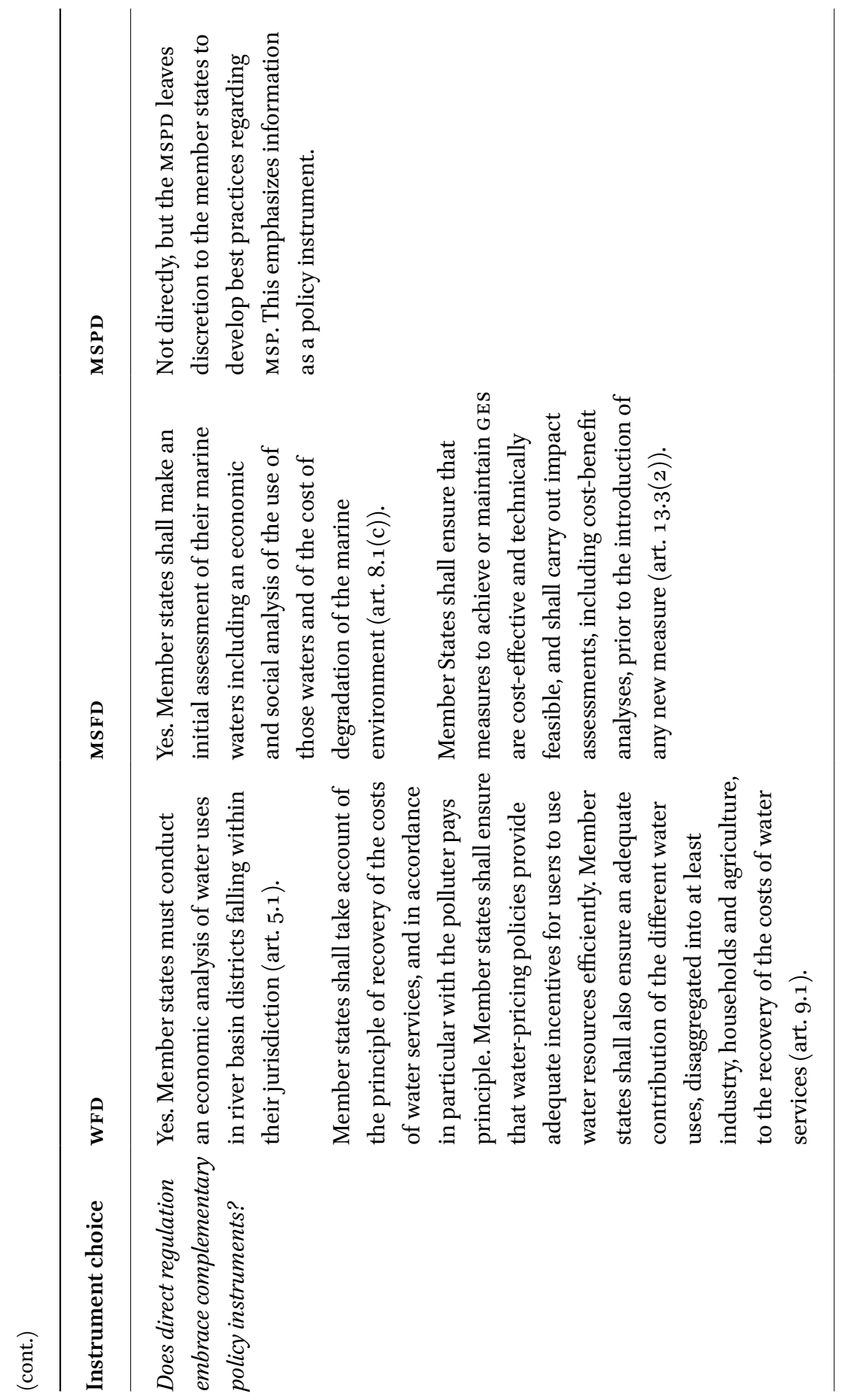




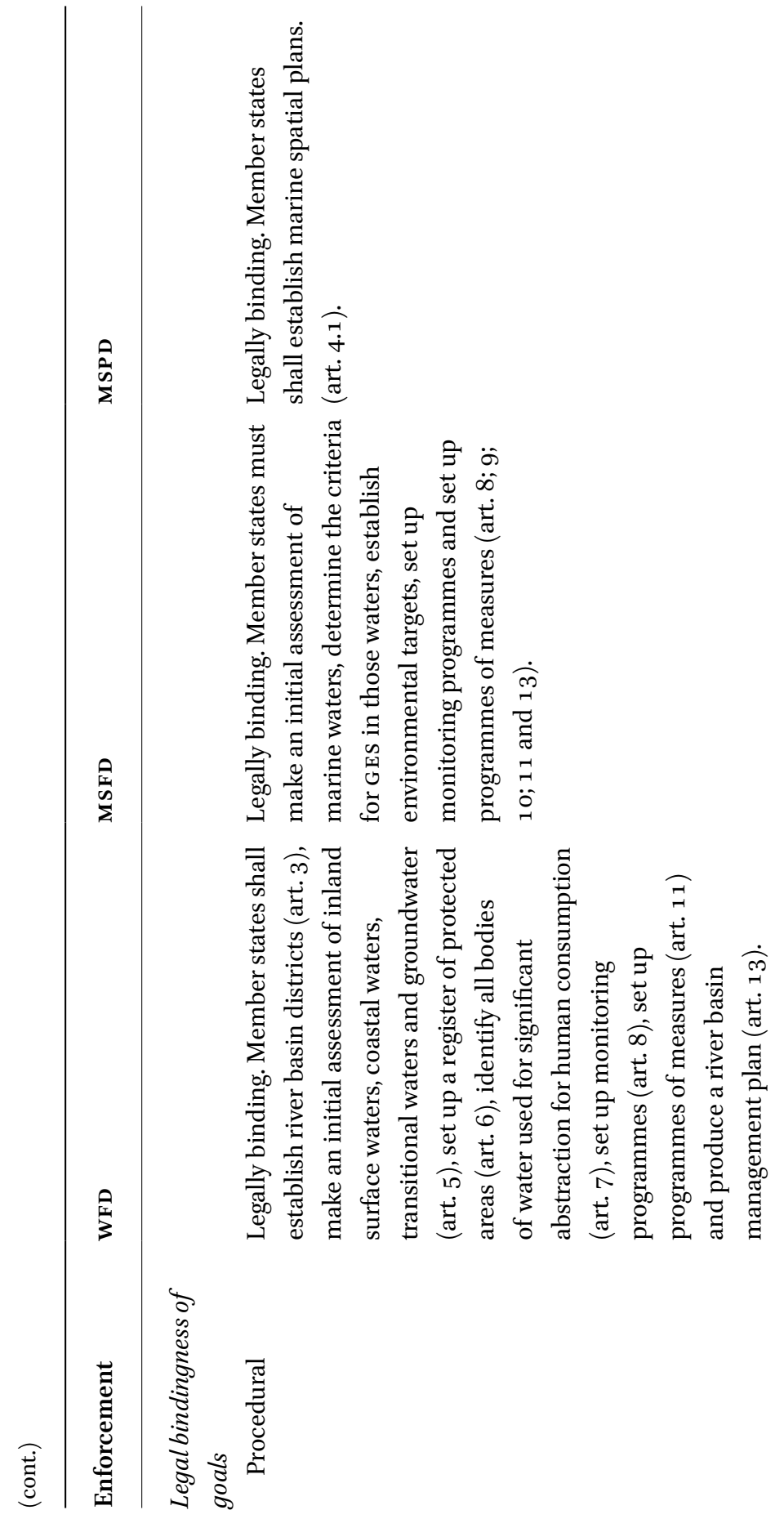




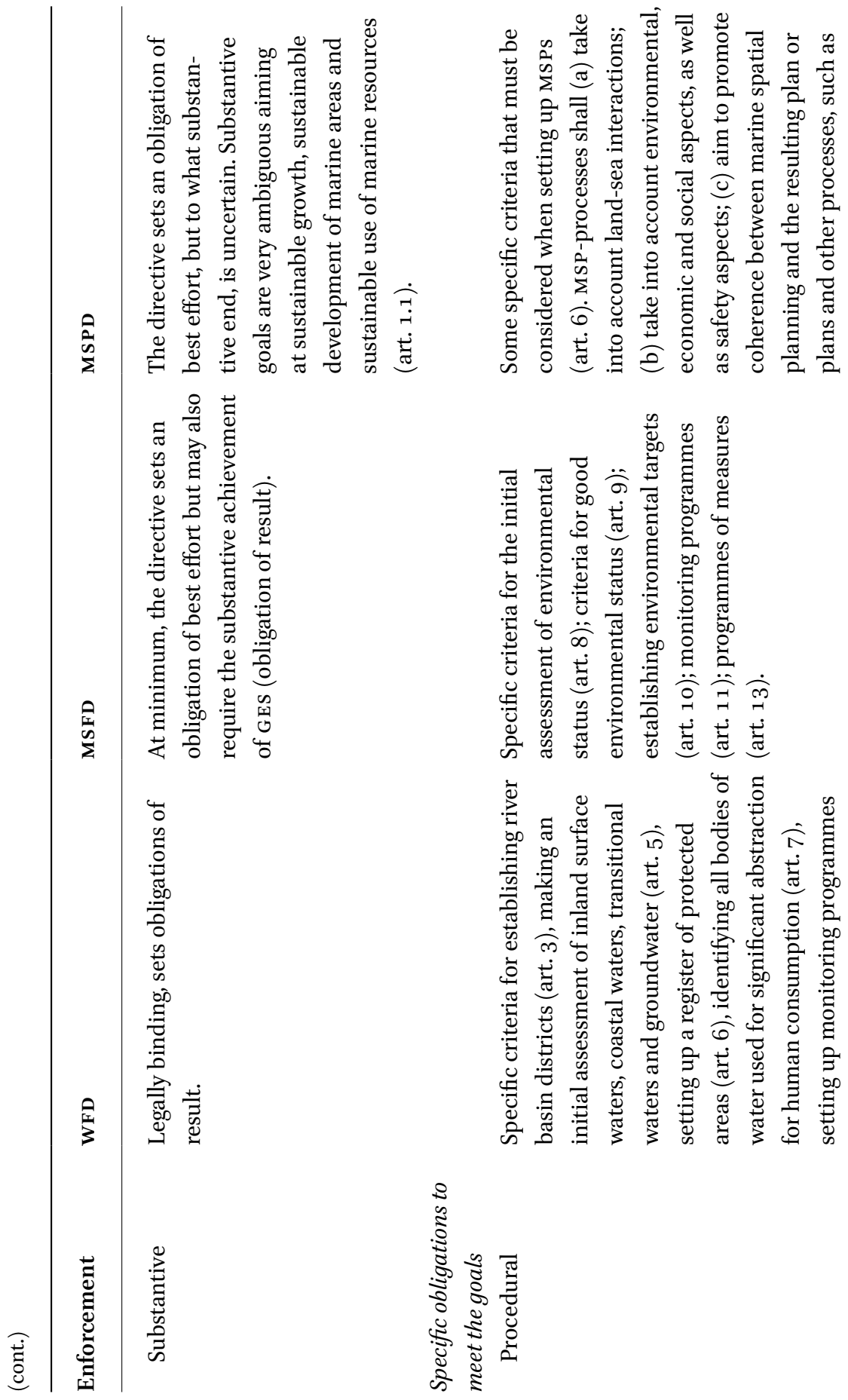




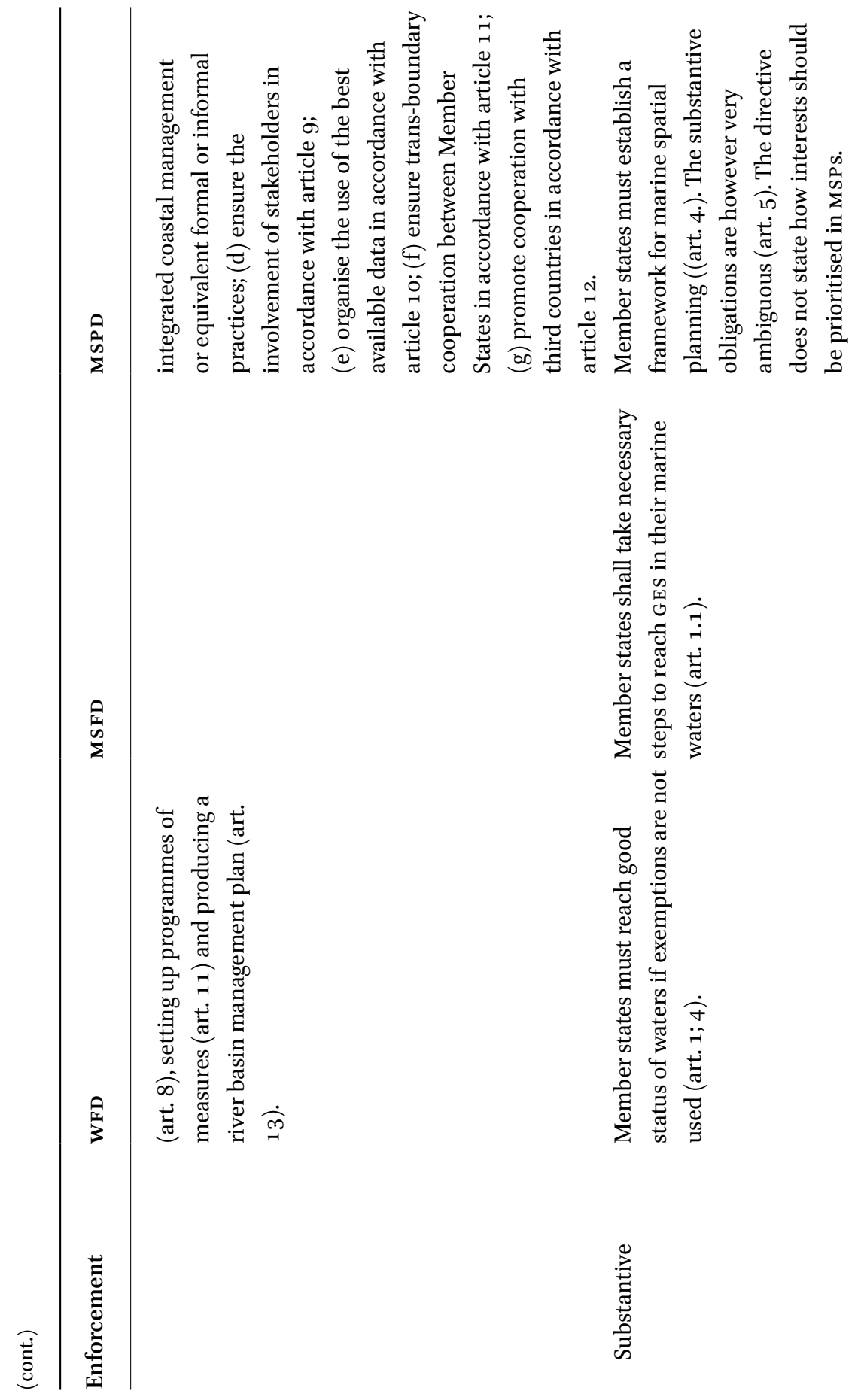




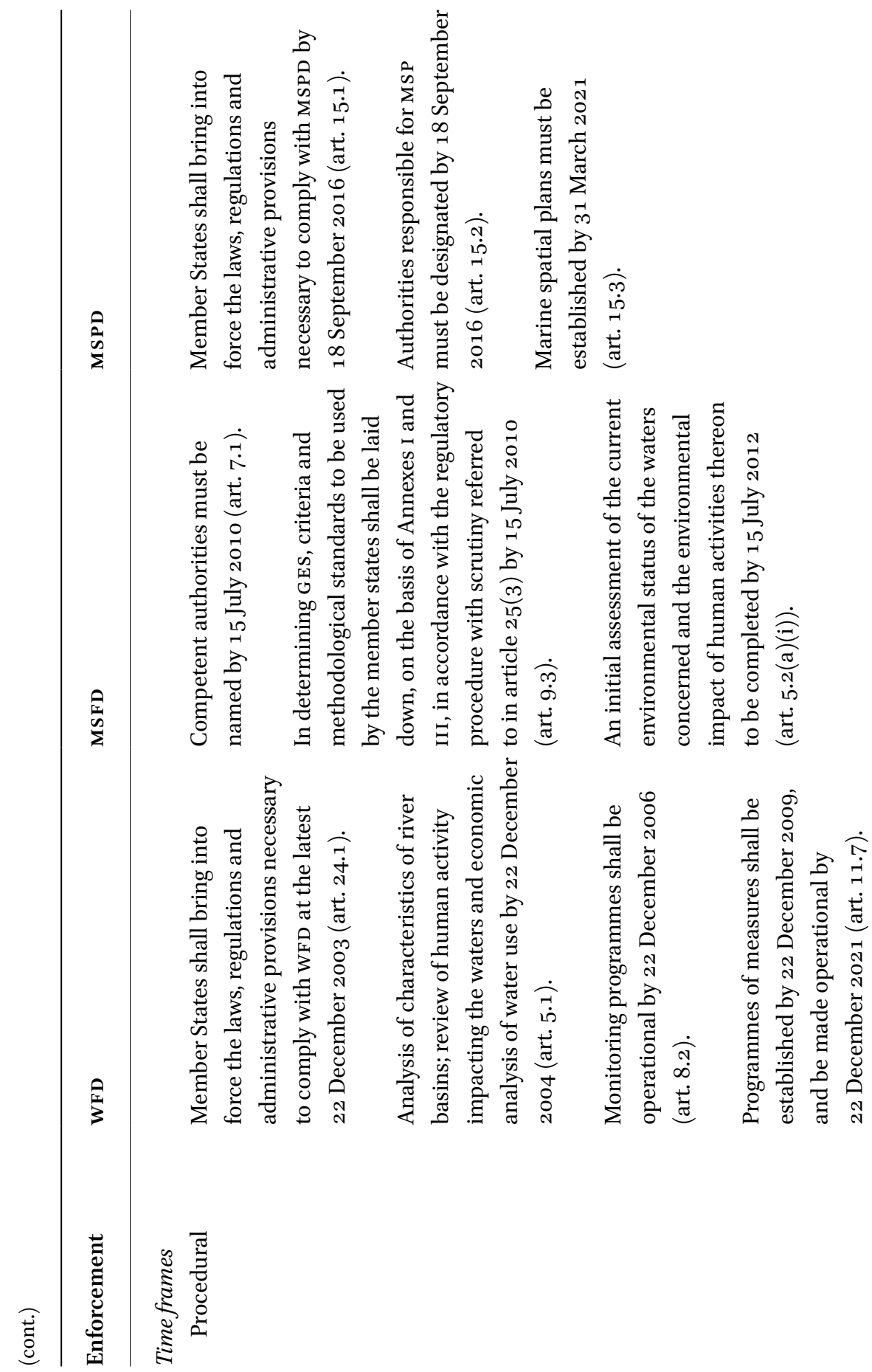




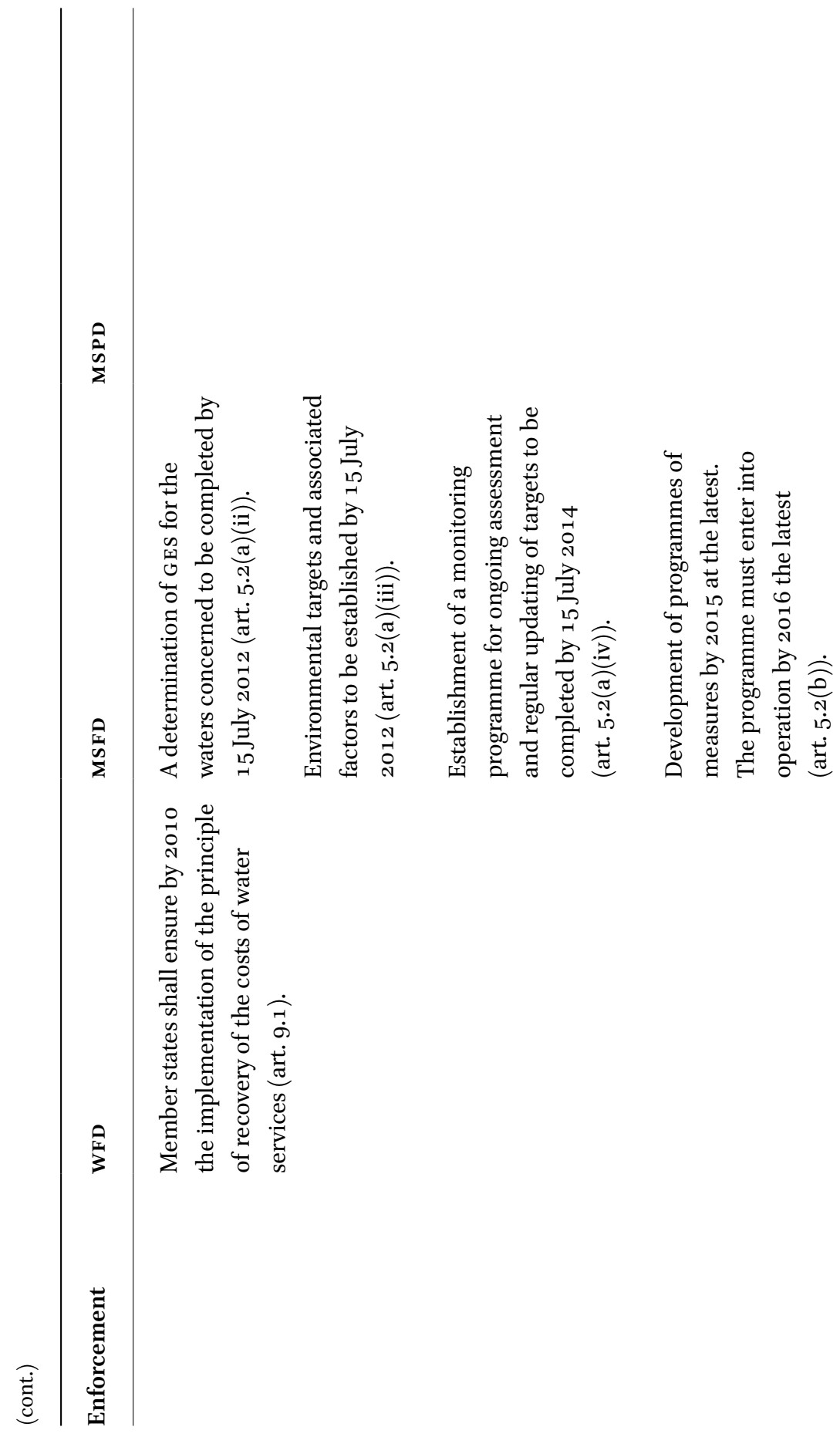




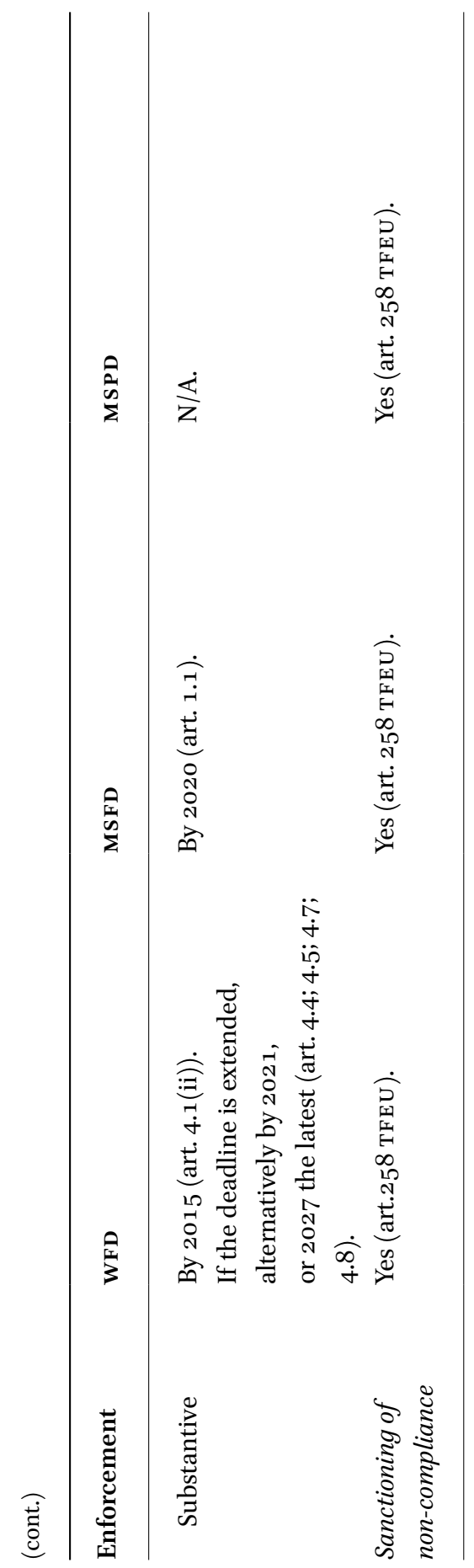

